\title{
Neue Gesichtspunkte zur Stratigraphie des mittleren und älteren Pleistozäns im Rheingletschergebiet
}

\author{
Von K. Schüdel und J. Werner, Freiburg i. Br.
}

Mit 9 Abbildungen im Text

$\mathrm{Zus}$ a m m e $\mathrm{n}$ a s $\mathrm{s}$ ung. Aus dem Rheingletschergebiet werden interglaziale Verwitterungshorizonte und eine überschliffene Nagelfluh beschrieben. Der bodenkundlich genauer untersuchte Horizont von Neufra bei Riedlingen (Donau) läßt Rückschlüsse auf seine Bildungszeit zu. Infolgedessen bekommt er allgemeine stratigraphische Bedeutung für den Rheingletscher: er trennt die bisher unter "Riß“ zusammengefaßte Altmoräne in Riß und Mindel. Dadurch verschieben sich alle älteren pleistozänen Schichtglieder um eine Stufe rückwärts.

A bstract: Beds weathered during an interglacial period and glacially polished "Nagelfluh" -conglomerates (fluvioglacial beds) of the area of the Rhine glacier are described. The horizon of Neufra (close to Riedlingen, Danube) is studied more thoroughly and leads to conclude on the time of its formation. Regarding the area of the Rhine glacier, this horizon is of a general stratigraphical importance. As it intercalates with the so-called Older Moraine ("Altmoräne") which was considered as "Riss" in age up to now, the sequence in question has to be divided into a Riss and a Mindel section. It follows that the preceding Pleistocene stages are older respectively.

\section{N H A L TS Ü B E R S I C H T}

I. Problemstellung

1. Der Rheingletscher

2. Was ist Mindel, was ist Riß?

3. Das Ertinger Schotterfeld

II. Neue Belege für die Grenze Mindel/Riß

1. Der Aufschluß von Neufra

2. Bodenkundliche Beobachtungen und Untersuchungen am Verwitterungshorizont von Neufra

3. Deutung des Profiles von Neufra

4. Der Aufschluß von Ertingen

5. Die Aufschlüsse von Rottum

III. Revision der Stratigraphie.

\section{Problemstellung}

\section{Der Rheinglets cher}

Der vorliegende Aufsatz beschäftigt sich mit den Ablagerungen des Rheingletschers im Donaugebiet, mit fluvioglazialen Kiesen, Moränen und den Bodenbildungen zwischen ihnen. Wegen der peripheren Lage dieser Terrassen- und Altmoränenlandschaft ist vom Ablauf der Geschehnisse mehr erhalten geblieben als im Beckeninnern. Die Wahrscheinlichkeit, in diesem Gebiet eine Vollgliederung aller weiten Vorstöße des Rheingletschers zu bekommen, ist also verhältnismäßig groß. Dies gilt auch für das älteste Pleistozän, in dem die Vorlandgletscher kleiner waren; denn zuerst bestand keine Entwässerung zum heutigen Hochrhein. Alle fluvioglazialen Aufschüttungen entwässerten zur Donau, mußten demnach in diesem Gebiet Spuren hinterlassen. Der Anschluß des Rheingletschers an den Aare-Rhein erfolgte sehr wahrscheinlich erstmals während der Günzeiszeit.

\section{Was ist Mindel, was ist $\mathrm{Ri} B$ ?}

Neue Arbeiten zur geologischen Landesaufnahme innerhalb des Gebietes der Altmoränen in Oberschwaben ließen erkennen, daß die Veröffentlichungen von A. PENCK u. E. Brückner (1901-1909), F. Weidenbach (1936, 1937a, b; 1951a), H. Graul (1952, 
1953), K. SChädEL $(1950,1952)$, A. SCHreiner $(1950,1951)$ noch keine voll befriedigende Lösung der stratigraphischen Fragen geben. Problematisch ist die Gliederung des mittleren und älteren Pleistozäns. Die Frage heißt: Was ist Mindel, was ist Riß?

Den Begriffen "Mindel“ und „Riß" (wie auch anderen im alpinen Vereisungsbereich gebräuchlichen stratigraphischen Bezeichnungen) haftet heute nur noch eine bedingte und leider etwas verschwommene Aussagekraft an. Die Gründe hierfür sind bekannt. Einmal entspringen sie aus der geringen Horizontbeständigkeit der eiszeitlichen Ablagerungen, kurz dem altbekannten Schachtelprinzip, zum anderen aber haben sie ihre Ursache in der räumlichen Beschränkung der einzelnen Arbeitsgebiete; denn seit der großen Arbeit von A. PENCK und E. BrüCKNER wurde das alpine Vereisungsgebiet nicht mehr zusammenhängend bearbeitet. Seither ist in einzelnen Gebieten viel Neues bekannt geworden, leider hat sich aber mit der Differenzierung der Kenntnis auch eine Abwertung und Verwirrung der ursprünglichen stratigraphischen Begriffe eingestellt. Es würde zu weit führen, die Entwicklung der einzelnen stratigraphischen Ansichten der verschiedenen Autoren hier aufzuführen, aber es sei gestattet, das darzulegen, was die Schöpfer der Begriffe A. PENCK und E. BRÜCKNER im Rheingletscher unter ihren Bezeichnungen verstanden haben und was die Verfasser darunter verstanden wissen wollen. Leider ist dadurch eine gewisse Vorwegnahme des Ergebnisses unumgänglich.

A. PencK’s Typlokalität für „R iß “ waren die großen Kiesgruben beiderseits des Rißtales nördlich Biberach, die größten Vertikalaufschlüsse, die es im Altmoränengebiet des Rheingletschers überhaupt gibt. Hier fand sich die Verzahnung von Moräne mit fluvioglazialen Schottern, die noch heute zu sehen ist und die A. PENCK bewog, wegen ihrer besonderen Eindringlichkeit den Namen des kleinen Rißflusses für die größte der diluvialen Vereisungen zu wählen. Er verknüpfte eine verhältnismäßig tiefe Terrasse, die sich besonders auf der Ostseite des unteren Rißtales ausdehnt, mit den Aufschlüssen von Biberach, eine Terrasse, die nach heutiger Ansicht in einer Endphase der Rißeiszeit geformt wurde.

Als mindeleiszeitlich sah A. PENCK vor allem die Schotter und Moränen auf der Ostflanke des Rheingletschers an, die den Lauf der württembergischen Rot und der Rottum begleiten. Diese Ansicht fußte auf Untersuchungen von A. Forster, dessen angekündigte Veröffentlichungen hierüber leider nie erschienen sind.

Faßt man zusammen, so kann gesagt werden, d a $ß$ A. P E N C K u n d E. B R Ü C K NER im Bereich des Rheingletschers unter den Namen "Riß “ und "Mindel“ die beiden nächst älteren selbständigen Eiszeiten vor Würm verstanden, deren Vorlandgletscher von gleicher Größenordnung waren. Sie übertrafen den der Würmeiszeit bedeutend.

In der Folgezeit stellte sich heraus, daß im Rheingletschergebiet ähnlich wie im IllerLechgebiet (B. EBERL 1930) im Altpleistozän mit einer stärkeren Differenzierung gerechnet werden muß. Das PENCK-BRÜCKNER'sche Schema reichte einfach nicht aus. Insbesondere unter dem Mindel PENCK's waren verschieden alte Ablagerungen zusammengefaßt. Hierbei handelt es sich um verschieden hohe Schotterterrassen, deren Höhendifferenzen zu Zeiten PENCK's mangels genauer topographischer Kartenunterlagen noch gar nicht erkannt werden konnten. K. Schädel (1950) und A. SChreiner (1950) haben gezeigt, daß als wichtigster stratigraphischer Horizont im Altpleistozän die $\mathrm{kr}$ istallinarmen $\mathrm{Sch}$ ot t e r zu betrachten sind, die tief verwittert unter die Altmoränen einstreichen. Sie wurden zunächst als Mindel I bezeichnet, weil an einigen wenigen Stellen in derselben Höhenlage, nur sicher jünger, auch $\mathrm{kr}$ istallin reiche Schotter unter den Altmoränen verwittert waren. Letztere wurden Mindel II genannt. Leider konnte die Verbreitung und stratigraphische Stellung dieser glazialen Serie nicht befriedigend beschrieben werden; denn es fehlte die Möglichkeit, sie scharf gegen das, was H. Graul als „Altriß “ bezeichnete, abzugrenzen. Heute ist es möglich, aufgrund neuer Aufschlüsse im Ried- 
linger Gebiet, die mit kürzlich von F. WEIDENBACH entdeckten Aufschlüssen übereinstimmen, diese Abgrenzung gegenüber der Rißeiszeit vorzunehmen, so daß wir bezüglich der Begriffe von „Riß“ und „Mindel“ folgendes aussagen können:

$\mathrm{Ri}$ i e is ze it lich sind die großen Kiesgruben beiderseits des Rißtales nördlich Biberach. Rißeiszeitlich ist ein Teil, und zwar vorwiegend der hangende Teil, der Altmoräne.

Mindeleiszeit lich sind die kristallinreichen Schotter, die mit Verwitterungshorizonten unter die Altmoräne einstreichen oder deren Nagelfluh von ihr abgeschliffen wurde. Mindeleiszeitlich ist ein zweiter, älterer Teil der Altmoräne in deren Liegendem, der nur in besonders günstigen Fällen von der hangenden Rißmoräne getrennt werden kann. Mit dieser Auffassung schließen wir uns an die Definition von A. Penck und E. BrüCKNer an.

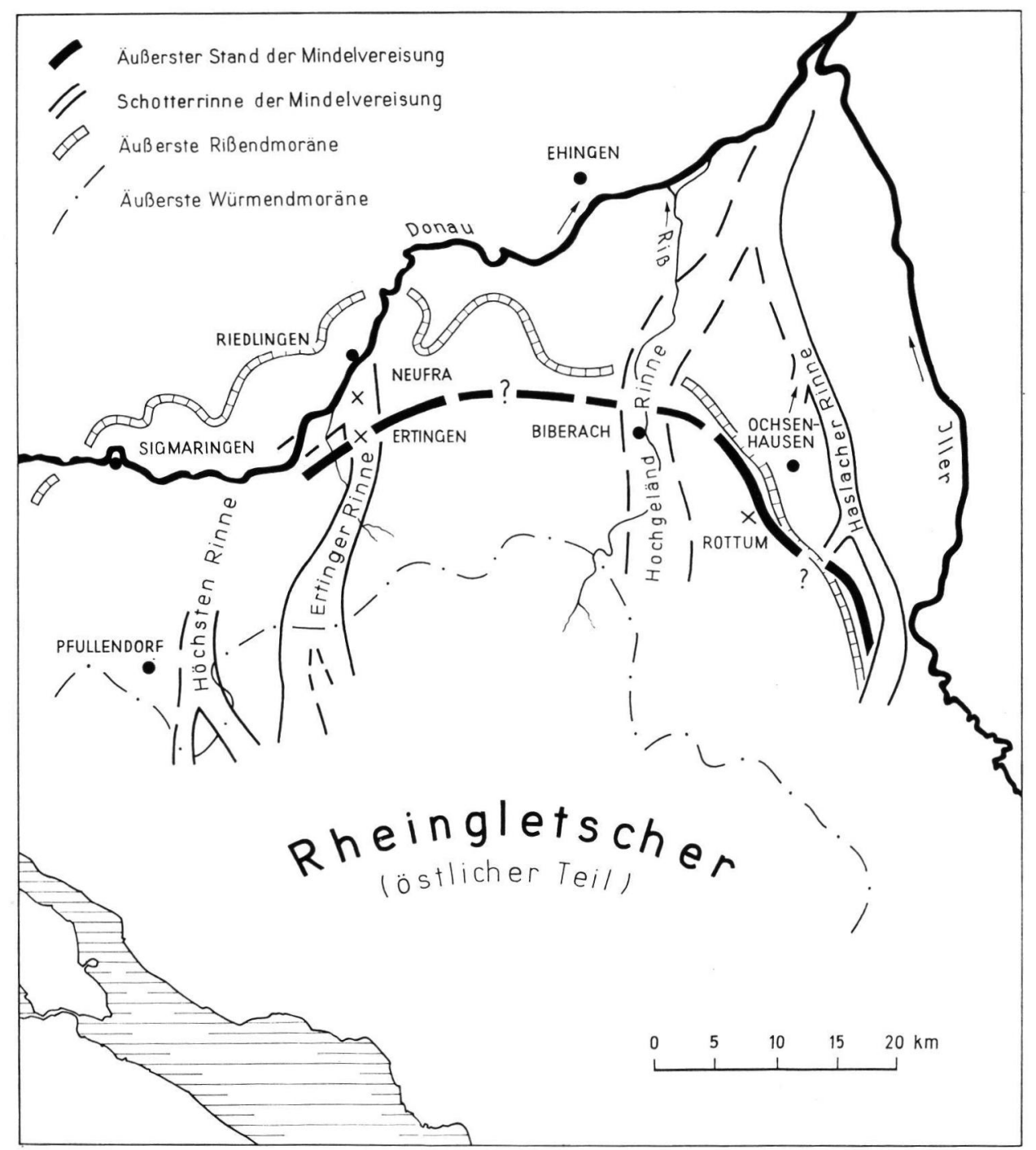

Abb. 1. Übersichtskarte des östlichen Rheingletschers. 
Günze is zeitlich sind - um eine Abgrenzung gegen das Altere zu geben die $\mathrm{kr}$ istallinarmen Schotter, die mit mächtigem Verwitterungshorizont unter die Altmoränen einstreichen (Zeil, Heiligenberg, Holzstöcke etc.).

Die um eine weitere Kaltzeit älteren Schotter von Eichen - Erlenmoos (nach PENCK \& Brückner, Weidenbach, Graul: Günz) fallen demzufolge in die „Do n a u K a l t z e i t “ EBERL's.

\section{Das Ertinger Schotterfeld}

Südlich von Riedlingen wird auf der Ostseite des Donautales ein fluvioglazialer Schotter angeschnitten, der unter Altmoränen hindurch weit nach Süden verfolgt werden kann (F. WeIDENBACH 1937). Er soll im folgenden als Ertinger Schotter bezeichnet werden (vgl. Abb. 1). Folgt man seinem Verlauf stromaufwärts, so bemerkt man, daß der Schotterkörper nördlich von Saulgau das Schwarzachtal quert und sich in SSW-Richtung unter der Äußeren Jugendmoräne hindurch bis in die Nähe der hochgelegenen Schotterriedel von Königseggwald hinzieht. Mit diesen läßt er sich profilmäßig und geröllpetrographisch verbinden.

Fast auf ihrem ganzen Verlauf ist die Ertinger Schotterrinne in die Altmoränenlandschaft eingebettet, d. h. sie tritt nicht als Erhebung hervor. Nur an ihrer Wurzel bekommt sie in dem Quer-Riedel von Königseggwald morphologisch Deckenschottercharakter, weshalb dieser von A. PENCK bereits zur Mindeleiszeit gestellt wurde. An der Donau liegt der Schotterkörper höher als die jüngeren Schotter nördlich Riedlingen, die gleichfalls von Altmoränen überdeckt sind. Der Basisunterschied beträgt hier $13 \mathrm{~m}$.

WEIDENBACH (1937) gliedert diesen Schotterkörper in sein Riß I ein. In dieser Alterseinstufung folgen ihm K. SCHÄDEL (1950) und H. Graul (1952), der einen Querschnitt durch das Riedlinger Becken beschreibt und dabei auch den Ertinger Schotter mit seinem hangenden Verwitterungshorizont erwähnt. Allerdings läßt sich seine Auffassung von zwei getrennten Akkumulationen nicht halten (Niveau 6 und 7). Ebenso sind einige andere Angaben von ihm durch die erweiterten Aufschlüsse überholt. Trotzdem ist es sein Verdienst, zuerst den Verwitterungshorizont erkannt und damit den Nachweis für ein Interglazial an dieser Stelle erbracht zu haben. (Graul nennt dieses „Vorriß“ in diesem Fall „Altriß“.)

Die Altersstellung des Ertinger Schotterfeldes ist demnach ein Zentralproblem für die Stratigraphie des Quartärs im Rheingletschergebiet. An Hand von zwei neuen Aufschlüssen ist es möglich, diese im einzelnen zu klären.

\section{Neue Belege für die Grenze Mindel/Riß}

\section{Der Aufschluß von Neufra}

In der Kiesgrube Neufra beim Vogelwäldle, $4 \mathrm{~km}$ SSE Riedlingen an der Donau, ist das im folgenden beschriebene Profil aufgeschlossen. Abb. 2 gibt ein zusammengefaßtes Bild des Aufschlusses wieder, wie es sich während der verschiedenen Abbaustufen in den Jahren 1960 und 1961 entwickelt hat.

Unter einem Oberflächen-Boden folgt eine Grundmoräne der Rißeiszeit. Überwiegend ist dies ein feinsandiger, grauer Geschiebemergel, in den in höheren Lagen, besonders im südlichen Teil der Wand, Kieslagen und Sandschmitzen eingebettet sind. Diese vermitteln den Übergang zu einer feinsandig-kiesigen Moräne (2a) und (2b). Die Einlagerungen im Geschiebemergel sind vom Gletscher gestaucht worden. Im Nordabschnitt der Wand ist eine alluviale Füllung eines kleinen Tälchens angeschnitten (1a). Letztere besteht aus verschwemmten Resten der verwitterten Moräne, aber auch aus Schwemmlöß.

Unter dem Geschiebemergel (2) liegt ein rotbrauner Verwitterungshorizon t (3) in einer Mächtigkeit (ohne Schlotten) von 1, 3 bis 1,8 m. In Schlotten reicht er beträchtlich tiefer in den liegenden Kies hinab, an einer Stelle bis über 4,00 m. Unter 


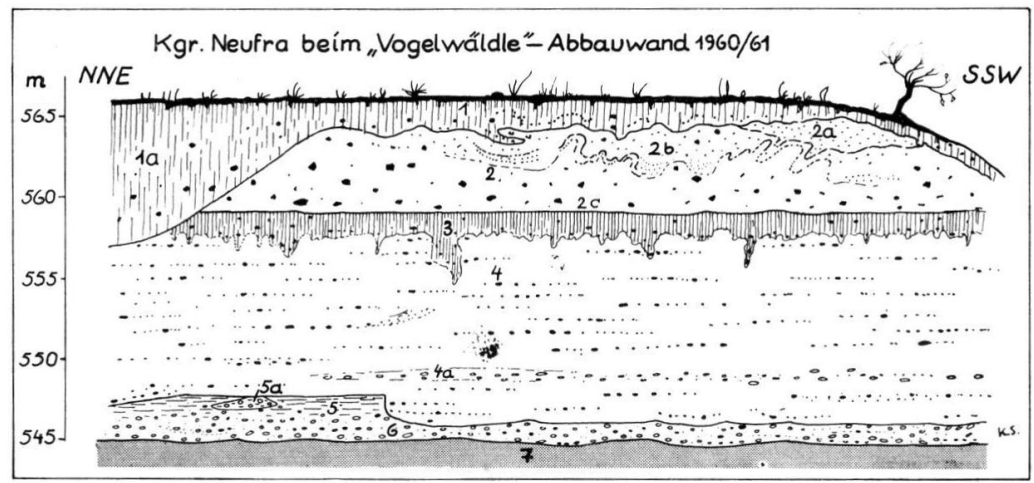

Abb. 2. Kiesgrube Neufra, beim „Vogelwäldle“ - Abbauwand 1960/61 (etwas vereinfacht). 1 Bodenbildung auf Moräne, 1a Tälchenfüllung aus verwitterter Moräne (alluvial), 2 Moräne (Riß), 2a Feinsandig-kiesige Moräne, 2b Stauchmoräne, 2c Geschiebemergel, 3 Interglazialer Verwitterungshorizont, 4 Schotter (Mindel), 4a Donaukieslage, 5 Auelehm mit Lösschnecken, 5a Fließerde im Auelehm als Rinnenfüllung (mit Holzresten), 6 Donau-Schotter, 7 Untere Süßwassermolasse.

dem Verwitterungshorizont folgt als Schicht 4 ein unverwitterter hochglazialer Schotter, der dem Ertinger Schotterfeld angehört. Er ist zügig geschichtet und führt mittelgroße Gerölle (durchschnittlich 3-5 cm). Das Kristallin der Alpen ist reichlich vertreten, dagegen ist der Anteil an Jurageröllen als Leitgeschiebe der Donau sehr gering. Erst an der Basis sind Lagen mit viel Lokalmaterial, vor allem Weißjura, daneben auch feinkiesiges Schwarzwaldmaterial (roter Granit, Porphyr usw.) zu erkennen; so z. B. in einer Lage, die ca. 1,5 m über dem liegenden Auemergel liegt (4a).

Die Untergrenze des fluvioglazialen Ertinger Schotters verläuft unregelmäßig. Etwa im nördlichen Drittel der Wand ist der Rand einer Rinne zu erkennen, an welchem die Untergrenze plötzlich einige Meter senkrecht nach unten springt und dann wieder waagrecht verläuft. Nördlich von dieser Rinne ist das Liegende ein Auelehm von braungelber Farbe, in den an einigen Stellen graue Schmitzen eingelagert sind und der oben $40-50 \mathrm{~cm}$ mächtig horizontal-schichtige Strukturen aufweist. Parallel dazu verläuft an der Obergrenze eine rötliche Verfärbung durch Eisenhydroxyd. Seine Mächtigkeit beträgt $0,7 \mathrm{~m}$, er ist stark schluffig mit reichlich beigemengtem Lößmaterial. Dazwischen sind einzelne Gerölle eingebacken. Nesterweise finden sich Lößschnecken und in den rinnenartigen, grauen von Schluff erfüllten Partien sind winzige verkohlte Holzreste enthalten, die nicht näher bestimmt werden konnten.

Nach unten mehren sich im Auelehm die eingebetteten Gerölle, so daß ein Ưbergang in die liegenden stark von Eisenhydroxyd verfärbten Schotter (6) entsteht. Bezeichnend für sie ist der Geröllbestand:

Tabelle 1

Geröllzusammensetzung des liegenden Schotters der Kiesgrube Neufra

\begin{tabular}{r|c|cc|c|c|c}
\hline Korngröße & $\begin{array}{c}\text { Jura-Kalke } \\
\%\end{array}$ & \multicolumn{2}{|c|}{ Kristallin *) } & $\begin{array}{c}\text { Kalk- } \\
\text { sandstein } \\
\%\end{array}$ & $\begin{array}{c}\text { Alpine } \\
\text { Kalke } \\
\%\end{array}$ & $\begin{array}{c}\text { Hornsteine } \\
\text { und Quarzite } \\
\%\end{array}$ \\
\hline$>15 \mathrm{~mm}$ & 68 & 8,5 & & 2 & 8,5 & 13 \\
$10-15 \mathrm{~mm}$ & 58 & 15 & $(3)$ & 3 & 6 & 18 \\
$7-10 \mathrm{~mm}$ & 50,5 & 16 & $(4)$ & 2 & 10 & 21 \\
$5-7 \mathrm{~mm}$ & 36 & 20,5 & $(8)$ & 6 & 11 & 26
\end{tabular}

*) Sicheres Schwarzwaldkristallin in Klammern. 
Der hohe Gehalt an Jurakalken und die Zunahme des Schwarzwaldkristallins in den feineren Korngrößen kennzeichnen diesen Schotter als Donaukies. Daneben findet sich aber auch alpines Material, in dem bezeichnender Weise die Hornsteine, Radiolarite und Olquarzite besonders reich vertreten sind. Dagegen ist der Prozentsatz der frischen blauen Kalke des Helvets oder des Ostalpins gering. Man kann schließen, daß es sich bei der Beimengung alpiner Schotter um Restmaterial handelt, das bereits durch einen Verwitterungsprozeß ausgelesen wurde, also um Restschotter auf sekundärer Lagerstät te.

Die Basis des Donaukieses auf dem Tertiär war im Verlauf des Abbaues nur selten, allerdings an verschiedenen Stellen, aufgeschlossen. Sie schwankt etwas in ihrer Höhenlage. Teilweise liegt normal körniger Donaukies $(3-5 \mathrm{~cm}$ ) auf den Sanden und Mergeln der unteren Süßwassermolasse. In einer flachen, rinnenartigen Vertiefung lag aber auf der Molasse eine grobe Basisschicht mit vielen Geröllen über Kopfgröße und Blöcken aus Basalt (vgl. F. Weidenbach 1951b) und Molassesandstein, deren größter Durchmesser $70-80 \mathrm{~cm}$ betrug.

Dr.h.c. E. Geiger hat die Gerölle der Moräne (Abb. 2; 2) und des fluvioglazialen Schotters (4) in Fortführung seiner Schotteranalysen (Gerger 1948), die sich über das ganze Rheingletschergebiet erstrecken, ausgezählt und nach Herkunftsgebieten bestimmt. Danach lassen sich das Hangende und das Liegende des Verwitterungshorizontes petrographisch nicht trennen. Die Ergebnisse der Zählungen E. GEIGER's werden in nächster Zeit veröffentlicht.

2. Bodenkundliche Beobachtungen und Untersuchungen am Verwitterungshorizont von Neufra

Der in der Kiesgrube Neufra zwischen fluvioglazialen Schottern im Liegenden und Moränen im Hangenden erhaltene rotbraune Verwitterungshorizont ist der ansehnliche Rest einer mächtigen interglazialen Bodenbildung und besitzt für das Rheingletschergebiet große stratigraphische Bedeutung. Er verdient daher eine eingehendere Untersuchung und Beschreibung, wobei die Frage nach seinem Aussaggewert über Dauer und Klimacharakter seines Bildungszeitraumes leitend sein soll.

\section{Mächtigkeit, Ober- und Untergrenze}

Der interglaziale Verwitterungshorizont konnte nur an einer Stelle des Aufschlusses näher untersucht werden. Diese Stelle ist auf Abb. 3 schematisch skizziert. Wie die Zeichnung zeigt, beträgt hier die geringste Mächtigkeit des Gesamtreliktes $1,55 \mathrm{~m}$; die größte Mächtigkeit ist, da rechts neben der liegenden Nagelfluh (C-Horizont) eine Verwitterungsschlotte unter die Sohle der Abbaustufe abtaucht, an dieser Stelle nicht genau zu ermitteln. Sie dürfte wenigstens $2 \mathrm{~m}$ betragen.

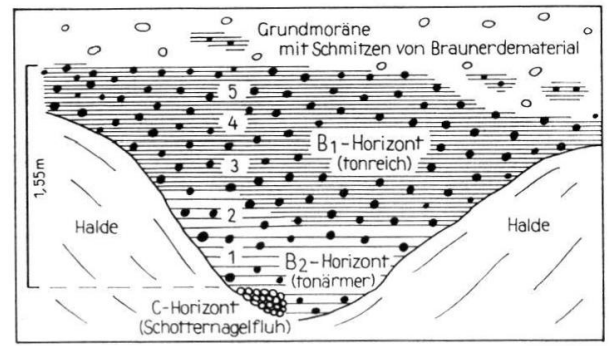

Abb. 3. Schematische Skizze des Verwitterungshorizontes. Die Ziffern bezeichnen die Entnahmestellen von Bodenproben.

Weder vom humosen Horizont $\left(A_{h}\right)$ noch vom Ton-Eluvialhorizont $\left(A_{l}\right)$ des ehemaligen Bodens sind irgendwelche Reste übriggeblieben. Das Bodenprofil wurde also durch den vorrückenden Gletscher der Riß-Vereisung bis in die B-Horizonte hinein gekappt. 
Die Grenze zwischen Bodenrelikt und hangender Grundmoräne ist millimeterscharf; doch finden sich in der hangenden Moräne - vor allem an der Basis der Grundmoräne, aber auch noch in den darüber folgenden endmoränenartigen Ablagerungen - zahlreiche zentimeter- bis dezimetergroße Schmitzen, die aus Bodenmaterial des Verwitterungshorizontes bestehen. Beim Überfahren schnitt also der Gletscher die oberen Bodenhorizonte haarscharf ab, wobei das abgehobelte Material vom Eis aufgenommen und in Form von größeren und kleineren Schmitzen in die Moräne eingeknetet wurde. - Andererseits konnte im Verwitterungshorizont etwa $4 \mathrm{dm}$ unter der Obergrenze eine einzelne horizontal verlaufende $1 / 2-3 \mathrm{~cm}$ starke Flaser aus hellgrauem, kalkreichem Geschiebemergel, sowie darüber vereinzelte dünne, mergelerfüllte Vertikalklüftchen beobachtet werden. Es muß sich dabei um Geschiebemergel-Infiltrationen auf ehemaligen Eisblättern handeln.

Während die Obergrenze des Verwitterungshorizontes als Eis-Erosionsfläche im großen und ganzen horizontal verläuft und nur kleinere Unregelmäßigkeiten aufweist, schwingt sich die Untergrenze, wie es bei B/C-Grenzen älterer Böden auf Kalkschottern üblich ist, girlandenartig auf und ab, um in einer einzelnen Schlotte etwa $4 \mathrm{~m}$ tief in das Ausgangsgestein, die liegenden Schotter, hinabzugreifen (vgl. Abb. 2).

Nach Aussagen von Kiesgrubenarbeitern besaß der Verwitterungshorizont zu Anfang des Abbaues, der in südwestlicher Richtung vorangetrieben wird, eine noch größere Mächtigkeit. Sie soll die jetzige um schätzungsweise einen Meter übertroffen haben. Die Mächtigkeitszunahme in südwestlicher Richtung käme nach diesen Aussagen durch ein leichtes Einfallen der Obergrenze, also der Erosionsfläche, zustande.

\section{Horizontierung, Profilbeschreibung}

Das Profil des Reliktbodens zeigt eine deutliche Zweiteilung in einen oberen tonreicheren $\left(B_{1}\right)$ und einen unteren tonärmeren $\left(B_{2}\right)$ Horizont. Die Grenze beider Horizonte ist unscharf und verläuft, soweit sich dies beobachten ließ, einigermaßen horizontal, jedoch um Beträge von einigen $\mathrm{dm}$ in der Höhenlage schwankend. Ob sie sich dem SchlottenRhythmus der Boden-Untergrenze angleicht, konnte nicht einwandfrei festgestellt werden.

$$
\text { Profilbeschreibung: }
$$

$\mathrm{B}_{1} \quad$ Kiesig-sandiger Lehm bis lehmig-sandiger Kies. Grobske'ettanteile über $50 \%$, bis ca. $50-\quad$ ca. $10 \mathrm{~cm}$ große Gerölle. Feinerde: lehmiger Sand bis sandiger Lehm (vgl. Tab. 2); $100 \mathrm{~cm}$ rötlich braun (vgl. Tab. 3). -

Sehr dicht gelagert. Boden bricht in unreglmäßigen Klumpen entlang den Geröllen und zeigt keinerlei Polyederstruktur mehr. Die Gerö'le weisen g'änzende rötlich-braune Beläge auf. In den obersten 3-4 dm schwach plattige Absonderung. Längliche Gerölle lassen keine bevorzugte Einrege'ung erkennen.

An einer von der Profilzeichnung nicht erfaßten Stelle nahe der Obergrenze zwei etwa dezimetergroße graue Flecken, von rostfarbenem Saum umgeben. Darunter horizontal verlaufendes Mangan-Eisen-Band.

$\mathrm{Ab}$ und zu fleckige Mangan-Eisen-Bestege auf den Gerölloberflächen. Vereinzelt auch schwarze unrege'mäßige Flecken in der Feinerde (= verdrückte ehemalige Mnbestege auf Polyeder-Grenzflächen). - Sehr schwach kalkhaltig (durch sekundäre Aufkalkung); keine Karbonatgerölle.

In der Feinerde isoliert vorkommend scharfkantige, stengelige Splitter von ausgelaugten alpinen Kiese'kalkgeröllen. Amphibolitgerölle noch formbeständig, lassen sich aber meist mit der Hand zerbrechen und zerbröse!n. Flyschsandsteingerölle ebenfalls noch erkennbar, zerfallen bereits bei leichtem Druck.

$\mathrm{B}_{2} \quad$ Lehmig-sandiger Kies. Grobske'ettanteil über 50\%. Feinerde: Lehmiger Sand (vgl. ca. 40- Tab. 2); Farbe deutlich ge'blicher als in $\mathrm{B}_{1}$.

$\max .400 \mathrm{~cm}$ Lose zerfallend, so daß die Entnahme einer Formprobe zur Dünnschliffherstellung nicht möglich war. Keine Tonbeläge auf den Gerö!loberflächen. - Bis auf kleine Restpartikel karbonatfrei.

Obergrenze unscharf, Untergrenze (B/C-Grenze) scharf, jedoch nicht durch Karbonatgerölle hindurchsetzend. 
Stengelig zerfallende ausgelaugte Kieselkalk-Gerölle in den Umrissen noch erhalten, Splitter also nicht isoliert wie in $\mathrm{B}_{1}$. Amphibolitgerölle noch hart mit intakter Oberfläche. Flyschsandsteingerölle lassen sich nicht zerdrücken, können aber mit dem Fingernagel angekratzt werden.

C An der Stelle geringster Mächtigkeit des Reliktbodens mäßig verbackene Schotternagelfluh (Bindezement nur in Form von Kornbrücken vorhanden) aus feinerem Kies $(2-3 \mathrm{~cm} \phi)$, nach unten rasch in lose, nur stellenweise leicht verkittete Schotter übergehend.

Tabelle 2

Korngrößenzusammensetzung der Feinerde im interglazialen Reliktboden der Kiesgrube Neufra

\begin{tabular}{l|c|c|c|c|c|c|c|c}
\hline \multirow{2}{*}{$\begin{array}{l}\text { Probe } \\
\text { Nr. }\end{array}$} & Horizont & $\begin{array}{c}\text { Tiefe unt. } \\
\text { Ober- } \\
\text { grenze }\end{array}$ & \multicolumn{5}{|c}{ Korngrößenzusammensetzung der Feinerde $<2.0 \mathrm{~mm}$} \\
\cline { 4 - 9 } & & $2.0-0.6$ & $0.6-0.2$ & $0.2-0.06$ & $0.06-0.02$ & $0.02-0.002$ & $<0.002$ \\
\hline 5 & $\mathrm{~B}_{1}$ & $10 \mathrm{~cm}$ & 14.8 & 18.8 & 13.3 & 19.3 & 10.5 & 23.5 \\
4 & $\mathrm{~B}_{1}$ & $40 \mathrm{~cm}$ & 10.1 & 28.1 & 17.7 & 16.1 & 9.4 & 18.4 \\
3 & $\mathrm{~B}_{1}$ & $70 \mathrm{~cm}$ & 15.1 & 20.6 & 25.6 & 17.5 & 5.8 & 15.9 \\
2 & $\mathrm{~B}_{2}$ & $100 \mathrm{~cm}$ & 25.6 & 20.4 & 19.8 & 14.0 & 6.4 & 13.6 \\
1 & $\mathrm{~B}_{2}$ & $130 \mathrm{~cm}$ & 29.3 & 30.4 & 16.7 & 10.5 & 3.1 & 10.4
\end{tabular}

Ursprüngliche Mächtigkeit und Profilausbildung des Interglazialbodens

Die ursprüngliche Mächtigkeit des Bodenprofils war größer als die des heutigen Reliktes. Um auf die ursprüngliche Mächtigkeit zu kommen, müssen zu der heutigen geringsten Mächtigkeit von $1,5 \mathrm{~m}$ wenigstens $0,5 \mathrm{~m}$ für den Ton-Eluviationshorizont $\left(A_{1}\right)$ plus den humosen Horizont $\left(A_{h}\right)$, welche zusammen mit einem nicht bekannten Anteil des B-Horizontes abgetragen wurden, hinzuaddiert werden. Man kommt somit auf eine $\mathrm{M}$ in $\mathrm{d}$ e s t mächtigkeit von $2 \mathrm{~m}$ (ohne Schlotten), also auf eine Mächtigkeit, die mindestens doppelt so groß war wie diejenige der postglazialen Bodenbildungen auf Würmschottern der Umgebung $(0,8-1 \mathrm{~m})$.

An der autochthonen Bildung des gesamten Bodenmaterials besteht kein Zweifel. Die horizontale Lage des ganzen Verwitterungshorizontes zeigt, daß die Bodenbildung auf der ebenen Oberfläche einer Schotterterrasse erfolgte. An eine teilweise Anhäufung von allochthonem Bodenmaterial durch Solifluktion zu Beginn der folgenden Eiszeit ist daher nicht zu denken. Wohl aber besteht die Möglichkeit, daß der abgetragene Oberboden aus einer die Schotterterrasse überdeckenden dünnen Auelehm- oder Lößlehmschicht hervorgegangen war, daß es sich also um ein zweischichtiges Bodenprofil handelte.

Mit der Verwendung des Horizontsymboles $A_{1}$ wurde bereits die bodentypologische Deutung des Reliktbodens als lessivierte Braunerde („Para-Braunerde“) vorweggenommen. Dieser heute im oberschwäbischen Quartärgebiet flächenmäßig bedeutendste Bodentyp ist charakterisiert durch seinen infolge der mechanischen Ton-Eluviation (Lessivierung) ${ }^{1}$ ) an Ton etwas verarmten $35-50 \mathrm{~cm}$ mächtigen Oberboden $\left(A_{h}+A_{l}\right)$, der sich sehr deutlich von dem infolge der Ton-Illuviation tonreicheren $\mathrm{B}_{\mathrm{i}}$-Horizont abhebt. Nicht lessivierte Braunerden kommen heute im ganzen oberschwäbischen Quartägebiet auf Riß-wie auf Würmmaterial von Natur kaum vor.

1) Die Lessivierung (mechanische Ton-Eluviation) ist grundsätzlich verschieden von der chemischen Tonzerstörung $=$ Podsolierung. Näheres hierüber (mit weiteren Literaturangaben) bei KUNDLER 1957. 
$\mathrm{Zu}$ unterscheiden sind im oberschwäbischen Quartärgebiet zwei verschiedene Ausbildungen der Para-Braunerden:

1. Die (jüngere) Para-Braunerde geringer Entkalkungstiefe, welche auf würmzeitliche Sedimente (Moräne und Schotter) und auf älteres, aber während des Würmglazials entblößtes Material beschränkt ist. Sie hat sich im Spät- und Postglazial gebildet. Ihre Mächtigkeit beträgt 0,8-1,2 m; ihr Profilaufbau ist im typischen Fall: $A_{h}-A_{l}-B_{i}-C$.

2. Die (ältere) Para-Braunerde großer Entkalkungstiefe, welche im Gebiet der Würmvereisung und auf Würmschottern - aułser in Gebieten sehr hoher Niederschläge (Allgäu) und auf Sanden - nicht vorkommt, sondern nur auf rißeiszeitlichen und älteren Sedimenten zu finden ist. Sie entstand im Riß/Würm-Interglazial und bildete sich im Postglazial weiter. Ihre Mächtigkeit beträgt im allgemeinen $2-3 \mathrm{~m}$ (ohne Schlotten); ihr Profilaufbau ist i.d.R.: $A_{h}-A_{l}-B_{i}-B_{v}-C$, wobei das Symbol $B_{i}$ den meist etwa $0,5-0,7 \mathrm{~m}$ mächtigen Ton-Illuviationshorizont und das Symbol $\mathrm{B}_{\mathrm{V}}$ die tonärmeren tieferen Teile des gesamten B-Horizontes bezeichnet.

Während also bei den typisch ausgebildeten Para-Braunerden geringer Entkalkungstiefe die Untergrenze des Ton-Illuviationshorizontes $B_{i}$ mit der Entkalkungsfront (Grenze $B / C$ ) zusammenfällt, bleibt bei den Para-Braunerden großer Entkalkungstiefe die Ton-Illuviation hinter der in das Ausgangsmaterial hinein vorrückenden Entkalkungsfront zurück, so daß zwischen beide der tonärmere $\mathrm{B}_{\mathrm{v}}$-Horizont zu liegen kommt. Hierbei ist allerdings zu beachten, daß der Unterschied im Tongehalt $z$ wischen $B_{i}$ und $B_{v}$ nicht allein auf die Ton-Illuviation zurückgeht, sondern auch auf die in dem als Bodenhorizont älteren $B_{i}$ länger wirksame Verwitterung und Tonneubildung.

Der Reliktboden von Neufra mit seiner Horizontabfolge $B_{1}\left(=B_{i}\right)-B_{2}\left(=B_{v}\right)$ und seiner ursprünglichen Mindestmächtigkeit von $2 \mathrm{~m}$ (ohne Schlotten) ist demnach bodentypologisch den Para-Braunerden großer Entkalkungstiefe zuzuordnen. Daß er tatsächlich der Lessivierung unterworfen war, zeigt sich eindeutig unter dem Mikroskop in einem Dünnschliff aus dem $\mathrm{B}_{1}$-Horizont, worin seine Tonsubstanz alle Eigenschaften besitzt, welche für die $\mathrm{B}_{\mathrm{i}}$-Horizonte der Parabraunerden charakteristisch sind: Hoher Dispergierungsgrad, starke Aggregatdoppelbrechung und deutliche Feinschichtung (vgl. Abb. 5).

\section{Zur Bodenfarbe als Klimaindikator}

Gewisse Hinweise auf den Klimacharakter des Interglazials, in welches die Bildung der hernach vom Hauptrißgletscher überfahrenen Bodenbildung fällt, gibt die auffallend rötlich-braune Farbe des tonreichen $B_{1}$-Horizontes. Dieser Farbton sticht deutlich $a b$ von dem etwas stumpferen Braun der Postriß-Bodenbildung auf der hangenden Moräne (vgl. Tab. 3), noch mehr aber von dem gelblichen Braun der Böden auf Würmschottern in der weiteren Umgegend.

Nun dürfen aber paläoklimatische Schlüsse aus rötlichen Farben fossiler Böden nur dann gezogen werden, wenn feststeht, daß die rötliche Farbtönung nicht durch das Ausgangsgestein bedingt sein kann - eine Erscheinung, die gerade in der weiteren Umgebung des Aufschlusses häufig zu beobachten ist. So finden sich am Südrande der Schwäbischen Alb vielerorts rötliche B-Horizonte von Para-Braunerden auf Riß-Kiesen. Diese auffallend rötlichen Bodenfärbungen sind jedoch gebunden an solche Schotter bzw. Endmoränen, welche zu einem beträchtlichen Anteil aus Weißjura-Kalken bestehen. Als Beispiel sei die alte Kiesgrube W Heudorf b. Meßkirch genannt. Die dort aufgeschlossenen Riß-Kiese entstammen zu einem hohen Prozentsatz der miozänen Juranagelfluh, die wiederum reichlich Weißjura-Massenkalk enthält. Das zugehörige Bodenprofil zeigt demzufolge in den B-Horizonten eine ähnliche rötlich-braune Färbung, wie sie für die Terra fusca auf tonarmen Kalken der Schwäbischen Alb bezeichnend ist, wie sie andererseits aber der fossile $\mathrm{B}_{1}$-Horizont in der Kiesgrube Neuf ra auch besitzt (vgl. Tab. 3).

Die das Ausgangsgestein für den fossilen Interglazialboden der Kiesgrube Neufra bildenden Schotter sind in ihren hangenden Partien praktisch frei von Donaumaterial und somit auch von Weißjurakalkstein-Geröllen. Eine Erklärung des auffallend rötlichen Farbtones im $\mathrm{B}_{\mathbf{1}}$-Horizont durch Besonderheiten im Ausgangsmaterial kommt somit nicht in Frage. Es liegt deshalb nahe, an eine klimatische Ursache zu denken. 
Tabelle 3

Bodenfarbwerte nach Munsell (Soil Color Charts) und durch Remissionsmessungen ermittelte Werte.

\begin{tabular}{|c|c|c|c|}
\hline Boden und Lokalität & $\begin{array}{l}\text { Farb- } \\
\text { beurteilung } \\
\text { im Gelände }\end{array}$ & $\begin{array}{c}\text { Bodenfarbe nach MuNSELL } \\
\text { (Probe auf weißem Papier } \\
\text { verrieben, trocken) }\end{array}$ & $\begin{array}{l}\text { Spektraler } \\
\text { Farbanteil } \\
\text { (Maßzahl für } \\
\text { Rotanteil) }\end{array}$ \\
\hline $\begin{array}{l}\text { Para-Braunerde auf weißjura- } \\
\text { reichen Rißschottern, Kgr. Heu- } \\
\text { dorf b. Meßkirch, } B_{1} \text {-Horizont }\end{array}$ & $\begin{array}{l}\text { hell } \\
\text { rötlich- } \\
\text { braun }\end{array}$ & $5 \mathrm{Y} \mathrm{R} 5 / 6-8$ bis $4 / 6-8$ & 0.427 \\
\hline $\begin{array}{l}\text { Para-Braunerde auf Würm- } \\
\text { schottern, Kgr. Schray E Singen } \\
\text { a. H., } B_{i} \text {-Horizont }\end{array}$ & $\begin{array}{l}\text { rötlich } \\
\text { braun }\end{array}$ & $7.5 \mathrm{Y} \mathrm{R} 5 / 6-8$ bis $4 / 6-8$ & 0.391 \\
\hline $\begin{array}{l}\text { Interglazialboden der Kgr. } \\
\text { Neufra auf Mindelschottern, } \\
\mathrm{B}_{\mathbf{1}} \text {-Horizont }\end{array}$ & $\begin{array}{l}\text { rötlich- } \\
\text { braun }\end{array}$ & $7,5 \mathrm{Y} \mathrm{R} 5 / 6$ bis $5 \mathrm{Y} \mathrm{R} 5 / 6$ & 0.380 \\
\hline $\begin{array}{l}\text { Oberflächenboden der Kgr. } \\
\text { Neufra auf Riß-Moräne, } \\
B_{\mathrm{i}} \text {-Horizont }\end{array}$ & $\begin{array}{l}\text { mittel- } \\
\text { braun }\end{array}$ & $10 \mathrm{Y} \mathrm{R} 5 / 3-4$ bis $4 / 3-4$ & 0.377 \\
\hline $\begin{array}{l}\text { Para-Braunerde auf Würm- } \\
\text { schottern, Kgr. Saulgau, } \\
B_{i} \text {-Horizont }\end{array}$ & $\begin{array}{l}\text { stumpf } \\
\text { graubraun }\end{array}$ & 10 Y R $5 / 3-4$ bis $4 / 3-4$ & 0.341 \\
\hline
\end{tabular}

Hierzu sind genauere Angaben möglich. Vergleichende Beobachtungen an Verwitterungsböden von Würmschottern im Rheingletschergebiet zeigen, daß im thermisch begünstigten westlichen Bodenseegebiet (vgl. Klima-Atlas von Baden-Württemberg) B-Horizonte mit einem auffallend rötlichen Farbton vorkommen (vgl. Tab. 3)2), wie er im nördlichen und östlichen Rheingietschergebiet nirgends auftritt ${ }^{3}$ ). Diese Para-Braunerden mit rötlich-braunem B-Horizont sind vor allem auf den Schottern und Endmoränen im Gebiet von Radolfzell-Singen in großer Fläche verbreitet.

Angesichts des allgemein bekannten, wenn auch im einzelnen noch wenig erforschten Zusammenhanges zwischen Temperaturklima, speziell Sommerwärme, und Bodenfarbe (Dehydratation der Eisen-3-Verbindungen bzw. teilweise Goethit-Hämatit-Umwandlung bzw. Eisenanreicherung) besteht daher Grund zu der Annahme, daß das Vorkommen solcher rötlich-brauner Farbtöne im B-Horizont der Würmschotter-Verwitterungsböden des westlichen Bodenseegebietes durch das thermisch günstige Regionalklima im Verein mit standörtlichen, lokalklimatischen Besonderheiten bedingt sei. Gemäß dieser Annahme müßten also im westlichen Bodenseegebiet die postglazialen Temperaturen wenigstens zu Zeiten so hoch gewesen sein, daß hier rötlichbraune Bodenfarben entstehen konnten, während die postglazialen Temperaturen im nördlichen und östlichen Rheingletschergebiet zur Bildung solcher Bodenfarben nicht ausreichten. Ein dem räumlichen Klimaunterschied zwischen westlichem Bodenseegebiet und der Riedlinger Gegend entsprechender zeitlicher Klimaunterschied könnte somit die Farbdifferenz zwischen dem rötlich-braunen $\mathrm{B}_{1}$-Horizont des Neufraer Interglazialbodens und dem stumpfen Braun der B-Horizonte auf den benachbarten Würmschottern erklären (vgl. Tab. 3).

Somit liegt es nahe, für das Bildungsklima des Neufraer Interglazialbodens etwas höhere Sommertemperaturen anzunehmen, als sie heute (im Postglazial) in der Riedlinger Gegend herrschen. Die Größenordnung der Differenz dürfte den sommerlichen Tempera-

2) Auf diese Beobachtungen hat schon vor Jahren Herr Dr. S. MüLleR, Stuttgart, aufmerksam gemacht.

3) Nach Abschluß des Manuskriptes erbrachten Farbremissionsmessungen an einer Serie von Proben im wesentlichen eine Bestätigung der subjektiven Farbbeobachtungen im Gelände und der ebenfalls subjektiven Farbvergleiche mit dem Munsell-Atlas. - In Tab. 3 ist in der 4. Spalte der mit Hilfe von Remissionsmessungen ermittelte spektrale Farbanteil als Maßzahl für den Rotanteil der Bodenproben aufgeführt. Über die Farbmeßmethode und ihre Ergebnisse wird an anderer Stelle ausführlich berichtet (Käsz und WERNER). 
turunterschieden zwischen der Riedlinger Gegend und dem westlichen Bodenseegebiet $\left.\left(1,0-1,5^{\circ}\right)^{4}\right)$ entsprechen.

Es ist noch zu berücksichtigen, daß die Rotfärbung im Neufraer Interglazialboden um wenigstens $1 \mathrm{~m}$ tiefergegriffen hat als in den Würmschotterböden des westlichen Bodenseegebietes, deren B/C-Grenze eine Tiefe von $1 \mathrm{~m}$ unter Gelände nicht überschreitet. Insgesamt wird man nicht fehlgehen, wenn man aus der auffallend rötlich-braunen Farbtönung des Neufraer Interglazialbodens auf ein Temperaturklima der Entstehungszeit schließt, welches das des Holozäns um einige wenige Grad übertroffen hat.

Die Mächtigkeit der Bodenbildung als Hinweis auf die Dauer des Interglazials

Ebenso wie bei der Heranziehung von Farben fossiler Böden zur Beurteilung des Entstehungsklimas ist bei der Heranziehung der Mächtigkeit fossiler Böden zu Aussagen über die Dauer der Bildungszeit kritische Vorsicht geboten. Denn die Mächtigkeit von Bodenbildungen ist nicht nur eine Funktion der Zeit, sondern auch eine solche des sich ständig ändernden Klimas.

So sind die braunen Verwitterungsböden auf Würmschottern im westlichen Bodenseegebiet und im Donaugebiet geringer mächtig (Entkalkungstiefe gegen $1 \mathrm{~m}$ ) als die entsprechenden gieichaltrigen Böden auf Würmschottern des Rheingletschers im Allgäu (Entkalkungstiefe um 1.3-1.5 m) bei im wesentlichen gleicher geröllpetrographischer Zusammensetzung des Ausgangsmaterials. Die regionale Differenzierung der Entkalkungstiefe entspricht der regionalen Differenzierung des Niederschlagsklimas (westliches Bodenseegebiet und Donaugebiet um 7-800 mm, nordwestliches Allgäu $1000-1500 \mathrm{~mm}$ ). Diese Beobachtungen bestätigen die theoretische Überlegung, daß ein feuchtes, kühleres Klima der Karbonatwegführung, mit der ja die Bodenbildung auf karbonatreichem Substrat einsetzt, günstiger ist als ein trockeneres, wärmeres.

Größere Mächtigkeit eines fossilen Bodens im Vergleich zu rezenten Bildungen kann somit entwedєr auf höherem Niederschlag oder auf längerer Dauer der Bildungszeit beruhen; es kann ihr aber auch eine Kombination beider Ursachen zugrunde liegen.

Im Falle des Neufraer Interglazialbodens ist indessen seine im Vergleich zu den entsprechenden rezenten Bodenbildungen große Mächtigkeit mit einer längeren Bildungszeit und nicht mit erheblich höheren Niederschlägen zu erklären. Denn ein wesentlich feuchteres Klima hätte deutliche Anzeichen von Staunässe im Boden hinterlassen müssen, wie dies an Para-Braunerden großer Entkalkungstiefe auf durchlässigen Würm-Substraten im niederschlagsreichen Allgäu bei Isny zu beobachten ist (schwache bis mäßige Pseudovergleyungen im B-Horizont). Eine Grau-Rost-Fleckigkeit ist aber im Neufraer Bodenrelikt nur an einer einzigen engbegrenzten Stelle (Durchmesser etwa $20-30 \mathrm{~cm}$, s. Profilbeschreibung) beobachtet werden, woraus geschlossen werden darf, daß das Neufraer Interglazial im großen und ganzen nicht erheblich feuchter als das Postglazial gewesen sein kann.

Somit läßt sich die Mindestdauer des Neufraer Interglazials durch Vergleich der rekonstruierten Mächtigkeit des Interglazialbodens mit derjenigen der rezenten Bodenbildungen auf Wüım-Substraten in der Umgebung grob angeben. Die Mindestmächtigkeit des Neufraer Interglazialbodens betrug, wie oben gezeigt wurde, $2 \mathrm{~m}$ (ohne Schlotten), wohingegen die Mächtigkeit der Böden auf Würmschottern in der Umgebung über ca. $1 \mathrm{~m}$ nicht hinausgeht. Berücksichtigt man noch, daß letztere im Gegensatz zum Neufraer Interglazialboden keine tiefgreifenden Schlottenbildungen aufweisen, so darf für den Neufraer Interglazialboden eine Bildungszeit veranschlagt werden, die mindestens 2 bis 3 mal so lange währte wie das Postglazial ( $>25000$ Jahre).

Auch ein Vergleich des Neufraer Interglazials mit dem Riß/Würm-Interglazial mag versucht werden. Wie oben gezeigt wurde, entspricht der Neufraer Interglazialboden nach Mächtigkeit und Profilausbildung den Para-Braunerden großer Entkalkungstiefe auf rißeiszeitlichem Material. Deren Entstehungszeit datiert vom Beginn des Riß/Würm-Inter-

4) Die Differenz zwischen den langjährigen Mitte'n der Vegetationsperiode von Radolfzell und von Saulgau (14 km SW Neufra) beträgt nach Ausküntten des Wetteramtes Freiburg $1.44^{\circ}$. 
glazials und geht bis heute, mit Unterbrechung durch die Kaltzeiten des Würm, in denen das gebildete Bodenmaterial teilweise - jedoch nicht in ebenen Lagen - durch Solifluktion wieder abgetragen wurde. Die Dauer des Neufraer Interglazials hat also der Größenordnung nach viel eher derjenigen des Riß/Würm-Interglazials als der des Postglazials entsprochen, wobei sehr wohl möglich ist, daß sie diejenige des Riß/Würm-Interglazials übertraf.

\section{Beobachtungen und Untersuchungen zur Verwitterungsintensität}

Nicht nur nach dem mengenmäßigen Anteil der Tonfraktion, sondern auch nach dem Grad der Verwitterungsintensität unterscheidet sich der $B_{1}$-Horizont des interglazialen Reliktbodens, wie aus der Profilbeschreibung hervorgeht, deutlich vom $\mathrm{B}_{2}$-Horizont. Während im $\mathrm{B}_{2}$-Horizont die Amphibolitgerölle noch harte, völlig intakte Oberflächen zeigen und die Flyschsandsteingerölle zwar entkalkt sind, aber sich nicht zerdrücken lassen, sind die Amphibolitgerölle im $\mathrm{B}_{1}$-Horizont oberflächlich angewittert, und die Flyschsandsteingerölle zerfallen unter mäßigem Druck der Hand. Hieraus geht hervor, daß der $\mathrm{B}_{1}$-Horizont einer intensiveren Verwitterung unterworfen war als der $\mathrm{B}_{2}$-Horizont und daß demzufolge der Unterschied im Tongehalt zu einem Teil mit der unterschiedlich starken Verwitterung, Tonfreisetzung und Tonneubildung erklärt werden muß. Wie das Dünnschliffbild des $\mathrm{B}_{1}$-Horizontes zeigt (Abb. 5), hat jedoch auch starke Toneinschlämmung aus dem (abgetragenen) Oberboden stattgefunden.

Entsprechende Unterschiede im Verwitterungsgrad zwischen $\mathrm{B}_{\mathrm{i}}$ - und $\mathrm{B}_{\mathrm{v}}$-Horizont sind an allen Para-Braunerden großer Entkalkungstiefe auf rißzeitlichem Material zu beobachten.

Quantitativ läßt sich die Verwitterungsintensität in der Schwermineralfraktion erfassen. Bei der Durchmusterung des gesamten Profils nach seiner Schwermineralzusam. mensetzung zeigte sich, daß der Granat im $\mathrm{B}_{\mathrm{i}}$-Horizont bis auf wenige Prozente ausgemerzt ist und daß die übriggebliebenen Körner bizarre Anlösungsformen aufweisen. Hierauf wurde die von WEYL (1952a und b) vorgeschlagene Methode der Ätzwertbestimmung angewandt, wobei aber nur der Granat Berücksichtigung fand. Hornblende und die Epidotgruppe erwiesen sich aus verschiedenen Gründen als ungeeignet.

Die Bestimmungen wurden an der Korngrößenfraktion $0.06-0.3 \mathrm{~mm}$ durchgeführt. Vor der Bromoform-Trennung wurden die Proben $1 / 2$ Std. in $15 \%$ iger $\mathrm{HCl}$ gekocht. Die Abgrenzung der drei von WEYL vorgeschlagenen Korrosionsgruppen geschah nach folgenden Gesichtspunkten:

Gruppe I: Nicht bis schwach geätzte Körner. (Keine oder nur undeutliche Korrosionserscheinungen.)

Gruppe II: Mäßig geätzte Körner. (Die Kornoberflächen zeigen deutliche Einbuchtungen; eingeschlossene Rutil- und Zirkonnadeln beginnen herauszuwittern.)

Gruppe III: Stark geätzte Körner. (Bizarre Korrosionsformen.)

Bei unklarer Zuordnung wurde das Korn eher der niedrigen als der höheren Aitzgruppe zugeschlagen. - Der Ätzwert errechnet sich nach WEYL wie folgt: Die Prozentanteile der drei Ätzgruppen an der Gesamtzahl der Granatkörner werden addiert, wobei Gruppe I mit dem Faktor 0, Gruppe II mit dem Faktor $1 / 2$ und Gruppe III mit dem Faktor 1 multipliziert wird. Auf diese Weise ergibt sich eine Relativzahl als brauchbares Maß für die Verwitterungsintensität.

Die Ätzwertbestimmung ist vor allem auch dann wertvoll, wenn es, wie im vorliegenden Falle, zu zeigen gilt, daß Schwankungen der Granatführung tatsächlich auf teilweise Ausmerzung durch Verwitterung und nicht auf primäre Sedimentationsschwankungen zurückgehen.

Das Ergebnis der Schwermineraluntersuchung geht aus dem Verlauf der Kurven der Granatführung und des Granat-Ätzwertes im Diagramm Abb. 4 hervor. Die starke Gegenläufigkeit beider Kurven im $\mathrm{B}_{1}$-Horizont des interglazialen Reliktbodens zeigt, daß der geringe Granat-Anteil tatsächlich auf einer Ausmerzung beruht.

Der sich schon in der verschieden starken Anwitterung petrographisch gleicher Gerölle äußernde unterschiedliche Verwitterungsgrad der Horizonte $\mathrm{B}_{1}$ und $\mathrm{B}_{2}$ des Interglazialbodens wird durch den Kurvenverlauf bestätigt. 


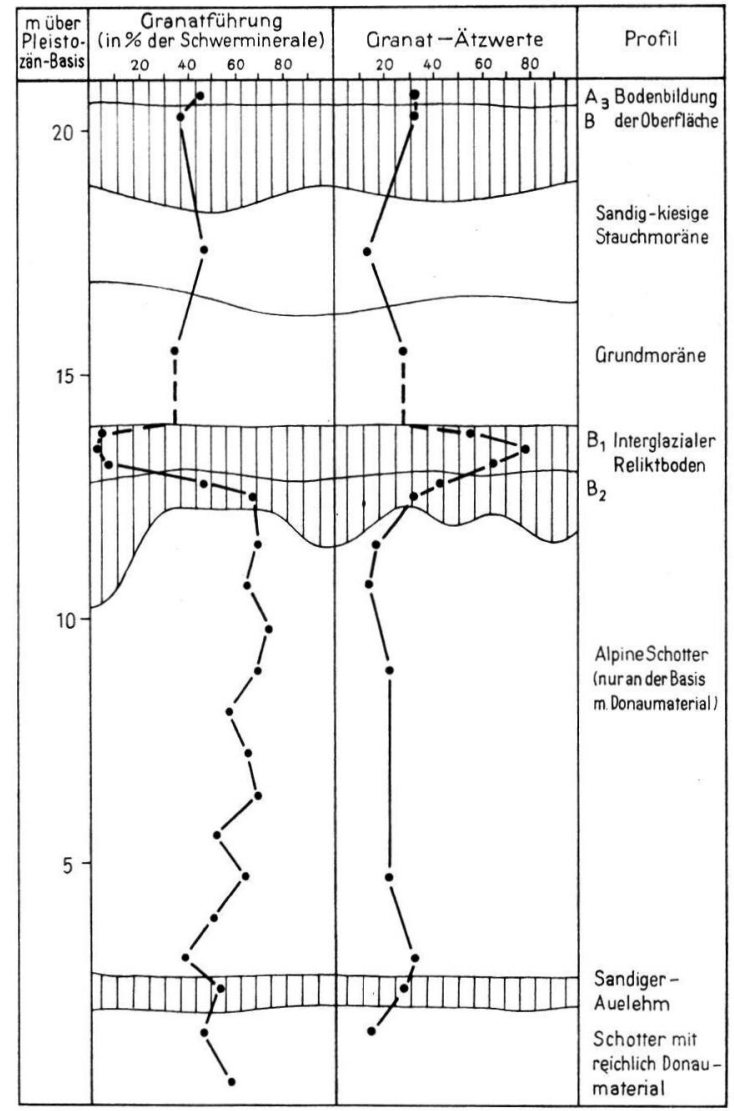

Abb. 4. Granatführung in \% der durchscheinenden Schwerminerale und Granat-Ätzwerte nach WEYL (1952) in der Kiesgrube Neufra.

Der Verlauf beider Kurven zeigt ferner, daß nur im $B_{1}$-Horizont des interglazialen Reliktbodens die Granate stark angegriffen und dezimiert wurden, wohingegen sie im $\mathrm{B}_{\mathrm{i}}$-Horizont des jüngeren, postrißzeitlichen braunen Oberflächenbodens und im älteren braunen Auenboden nur eine unsichere schwache (innerhalb der Fehlergrenzen liegende) oder gar keine Dezimierung aufweisen.

Dieser letztere Umstand wiederum erlaubt die Aussage, daß die Dezimierung der Granate im wesentlichen das Werk der interglazialen Verwitterung war und nicht der langen Verweildauer im tonigen Milieu überhaupt zuzuschreiben ist. Wäre dies der Fall, so müßte der ältere Aueboden eine mindest ebenso starke, wenn nicht noch stärkere Granatdezimierung als der interglaziale Reliktboden zeigen.

Neben dem Granat zeigen auch andere durchscheinende Schwerminerale im B $\mathrm{B}_{1}$-Horizont des Interglazialbodens deutliche Korrosionserscheinungen, welche im übrigen Profil nicht oder nicht in diesem Ausmaß auftreten. - Die Hornblenden sind sehr stark korrodiert und gebleicht, jedoch nicht deutlich dezimiert. - Die Minerale der Epidotgruppe, vor allem die Pistazite, zeigen sehr starke Zersetzung. Diese ist indessen auch im übrigen Profil zu beobachten und führte nicht zu einer merklichen Dezimierung. - Auffallend sind die Anzeichen deutlicher Korrosion, welche die als ziemlich stabil geltenden Minerale Staurolith und Disthen im $\mathrm{B}_{1}$-Horizont des Interglazialbodens erkennen lassen. In den Proben aus diesem Horizont - und nur hier - sind viele Staurolithe durchsetzt von 
schmutziggrauen, z. T. fast opaken, diffus verlaufenden Partien; die Farbe solcher Körner ist schmutzig braungelb bis schmutzig hellgelb bei deutlich nachlassendem Pleochroismus, und ihre Oberflächen sind leicht zerlappt. - Die Disthene dieser Proben sind großenteils von der Oberfläche her ziemlich angegriffen, z. T. auch entlang der Spaltrisse. -

Es kann somit aufgrund des Kurvenverlaufes der Granatführung und der Granatätzung sowie auf Grund zusätzlicher Beobachtung von Korrosion an sonstigen Schwermineralen ausgesagt werden, daß die Verwitterung im Interglazial von Neufra ungleich intensiver war als diejenige des Postglazials. Indessen darf aus der geringen Granatätzung im $\mathrm{B}_{1}$-Horizont des postrißzeitlichen Oberflächenbodens nicht ohne Vorbehalt auch auf eine im Vergleich zum Interglazial von Neufra geringere Verwitterungsintensität des Riß/ Würm-Interglazials geschlossen werden, da der Riß/Würm-interglaziale $\mathrm{B}_{\mathrm{i}}$-Horizont während des Würmglazials an der geneigten Oberfläche zum Teil der Solifluktion zum Opfer gefallen sein könnte.

Wie weit der im $\mathrm{B}_{1}$-Horizont des Interglazialbodens festgestellte vergleichsweise hohe Verwitterungsgrad auf die lange Dauer des Interglazials und wie weit er auf ein im ganzen etwas wärmeres - und vielleicht auch gleichmäßiger feuchtes - Klima zurückgeführt werden muß, kann auf Grund dieser Beobachtungen vorläufig nicht entschieden werden.

\section{Mikroskopische Untersuchung der Tonsubstanz}

Das Dünnschliffbild vom $\mathrm{B}_{1}$-Horizont des interglazialen Bodenreliktes zeigt dieselbe hochdisperse aggregat-doppelbrechende Tonsubstanz mit Feinschichtung infolge von Tontransport in den Bodenhohlräumen (Lessivierung) ${ }^{5}$ ), wie sie für den $\mathrm{B}_{\mathrm{i}}$-Horizont der ParaBraunerden auf oberschwäbischen Würm- und auf Riß-Sedimenten charakteristisch ist. Es besteht somit kein Zweifel, daß es sich bei dem ursprünglichen Interglazialboden von Neufra um eine Para-Braunerde mit $\mathrm{A}_{1}-\mathrm{B}_{\mathrm{i}}-$ Horizontierung handelte.

Auch bei stärkster Vergrößerung ist in der Tonsubstanz keinerlei Flockung, Eisenausscheidung oder dgl. erkennbar. Die Tonsubstanz unterscheidet sich in ihren optischen Eigenschaften nicht von der Tonsubstanz in einem Vergleichs-Dünnschliff aus dem $\mathrm{B}_{\mathrm{i}}$-Horizont einer Para-Braunerde auf Würmschottern bei Saulgau, wenn man absieht von dem im Interglazialboden etwas rötlicheren Farbton. Anzeichen für eine Kolloid-Alterung im Interglazialboden sind somit auf optischem Wege nicht feststellbar.

Im Körnerpräparat wurde die Lichtbrechung der Tonpartikel bestimmt. Sie liegt beim interglazialen wie beim postglazialen Boden ohne merklichen Unterschied um 1.57.

Ein deutlicher Unterschied zwischen dem $\mathrm{B}_{\mathrm{i}}$-Horizont des Interglazialbodens und dem $\mathrm{B}_{\mathrm{i}}$-Horizont des Vergleichsbodens auf Würmschottern zeigt sich indessen in der Boden $\mathrm{struktur}$ (vgl. die Abb. 5 und 6). Die Hohlräume im ersteren sind in stärkerem Maß von Tonsubstanz erfüllt als in letzterem. Ferner ist die Tonsubstanz des Interglazialbodens in viele kleine Schollen von der mittleren Größe $0.1-0.5 \mathrm{~mm}$ zerbrochen, welche in sich feingeschichtet sind, teilweise einheitlich auslöschen und einen schwachen Pleochroismus zeigen.

Diese Zerteilung der doppelbrechenden Tonsubstanz in Bruchstücke ist die Folge der Durchbewegung, welche der Interglazialboden im Gegensatz zu den Postwürm-Böden erfahren hat, und zwar sowohl durch Kryoturbation als auch durch die Druck- und Scherkräfte des sich über den Boden hinweg bewegenden Riß-Gletschers. Ahnliche Erscheinungen sind in den tieferen Horizonten von Para-Braunerden großer Entkalkungstiefe auf RißSubstraten zu beobachten, dort als Folge der würmeiszeitlichen Kryoturbation.

\section{Sonstige tonmineralogische Untersuchungen}

Zur Bestimmung der Tonminerale wurde eine Probe vom $\mathrm{B}_{1}$-Horizont des Neufraer Interglazialbodens röntgenographisch, differential-thermoanalytisch und elektronenmikroskopisch untersuch ${ }^{6}$ ), und zwar jeweils zusammen mit einer Vergleichs-Probe aus dem $\mathrm{B}_{1-}$

5) Näheres hier über bei Kublena 1948 und Altemüller 1956.

6) Herr Dr. Brauner und Herr Dr. TABORSKY vom Mineralogischen Institut der Universität Freiburg haben entgegenkommenderweise die röntgenographischen und differentialthermoanalytischen Bestimmungen und Fräulein Dr. Braun vom Radiologischen Institut der Universität Freiburg die elektronenmikroskopischen Aufnahmen besorgt. Ihnen sei für ihre Mitarbeit herzlich gedankt. 

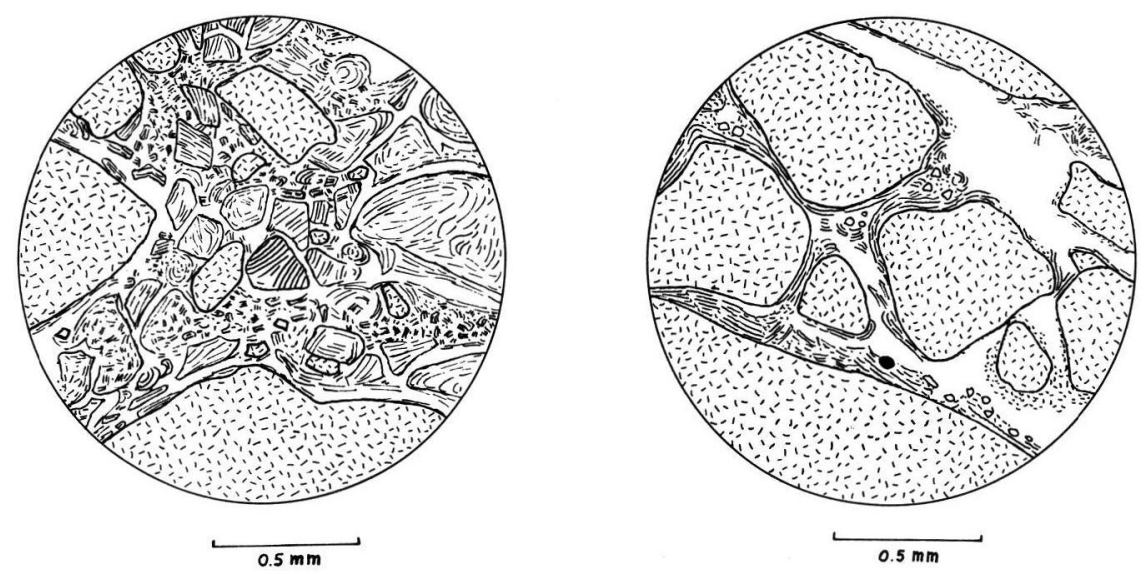

Abb. 5 (links). Dünnschliffbild aus dem $\mathrm{B}_{1}$-Horizont des interglazialen Bodenreliktes von Neufra. Gerölle und grobe Sandkörner: unregelmäßig gestrichelt. Doppelbrechende Tonsubstanz: parallel verlaufende Linien. Nichtdoppelbrechende Tonsubstanz: Punktiert. Hohlräume: weiß. Die doppelbrechende Tonsubstanz ist zerschuppt, gestaucht und in zahlreiche Schollen zerbrochen, die zum Teil sehr ausgeprägte Feinschichtung besitzen (Scholle in Bildmitte). Einzelne Schollen löschen einheitlich aus und zeigen relativ hohe Interferenzfarben (durch zonare Linien angedeutet). - Abb. 6 (rechts): Dünnschliffbild aus dem $\mathrm{B}_{\mathrm{i}}$-Horizont einer Para-Braunerde auf Würmschottern (Kiesgrube S Saulgau). Signaturen wie bei Abb. 5. Die doppelbrechende Tonsubstanz schmiegt sich den Gerölloberflächen an und zeigt Feinschichtung. Sie befindet sich noch am Ort ihrer Entstehung.

Horizont desselben Para-Braunerde-Profils auf Würmschottern in einer Kiesgrube $S$ Saulgau, aus welchem auch der bei der Dünnschliff-Untersuchung herangezogene Vergleichs-Dünnschliff stammt.

Hierbei konnten der tonmineralogischen Zusammensetzung nach keine Unterschiede zwischen dem $B_{1}$-Horizont des Interglazialbodens und dem $B_{i}$-Horizont der Würmschotter-Para-Braunerde festgestellt werden. Der röntgenographische Befund ergab, daß die Tonsubstanz in beiden Fällen sehr wahrscheinlich aus einem dioktaedrischen Illit-Mineral (Di-Illit, Sericit) besteht, wobei der amorphe Anteil nur gering sein kann. Auch die Differential-Thermoanalyse spricht für Illit; Montmorillonite sind nach den D.T.A.-Kurven auszuschließen.

Im elektronenoptischen Bild findet man ebenfalls keine Unterschiede zwischen der Tonsubstanz des Interglazialbodens und derjenigen der Würmschotter-Para-Braunerde. Kaolinite sind nach dem elektronenoptischen Bild ausschließbar.

Insgesamt zeigen die tonmineralogischen Untersuchungen, daß die 'Tonbildungsvorgänge bei der Verwitterung der Mindelschotter im Mindel/Riß-Interglazial sich nicht erkennbar unterschieden von den Tonbildungsvorgängen bei der Verwitterung der Würmschotter im Postglazial und daß im Interglazialbodenrelikt von Neufra keine Alterungserscheinungen in Form von Tonmineralumwandlungen nachweisbar sind.

\section{Deutung des Profiles von Neufra}

Ausgangspunkt für die Deutung ist der Verwitterungshorizont (Abb. 2; 3). Wie die vergleichende bodenkundliche Untersuchung gezeigt hat, war seine Bildungszeit ein echtes Interglazial, dessen Temperaturen im ganzen ungefähr denen des Postglazials entsprachen, sehr wahrscheinlich aber zeitenweise um einige Grad über den heutigen lagen, und dessen Dauer die des Holozäns um mindestens das Doppelte übertraf.

Die Grundmoräne (2, 2a, 2b) sowie ihre Einlagerungen im Hangenden sind ganz ohne Zweifel in der Rißeiszeit (Biberacher Stufe) abgelagert worden. Die kristallinreichen fluvioglazialen Schotter $(4,4 a)$ im Liegenden des Verwitterungshorizontes, die dessen Ausgangsmaterial darstellen, müssen demzufolge der nächstälteren Eiszeit, also der Mindeleiszeit, entstammen. Der Verwitterungshorizont selbst verdankt seine Entstehung der Warmzeit zwischen Mindel und Riß. 
Die aus den vergleichenden bodenkundlichen Untersuchungen gewonnenen Erkenntnisse gestatten den Versuch, dieses Interglazial in die aus dem nordischen Vereisungsgebiet bekannte Abfolge der pleistozänen Warmzeiten einzustufen. Ihrem klimatischen Charakter nach kommen hiervon wohl nur das Eem- und das Holstein-Interglazial in Frage, von denen das erstere wegen zu geringen Alters auszuscheiden hat. Von der „Wärmezeit zwischen Alt- und Mittelriß“ (Hemmoor) Kolumbe's (1953), vom „Ohe-Interglazial“ von DER Brelie's (1955) bzw. von der „Treene-Wärmeschwankung“ PiCARD's (1960) sind bis heute keine marinen Transgressionen bekannt. Eine solche ist aber für die Entstehungszeit des Interglazialbodens von Neufra, welche zumindest gleich warm oder etwas wärmer war und sehr viel länger andauerte als das Holozän, anzunehmen.

Somit kommt am ehesten das Holstein-Interglazial als mögliche Entstehungszeit der Bodenbildung von Neufra in Frage. Die Vorkommen von Buxus sempervirens und Vitis silvestris in Norddeutschland und in den Niederlanden (Woldstedt 1958, FlorschüTz 1957) außerhalb ihrer heutigen Areale bezeugen für das Holstein-Interglazial einen wärmeren Abschnitt, dessen Temperaturen die heutigen um einige Grad übertroffen haben müssen (vgl. z. B. Arealkarte von Buxus sempervirens bei WaLter 1954, S. 174). Der Gesamtaspekt der Waldentwicklung im Holstein-Interglazial (zuletzt Hallik 1960) andererseits zeigt, daß die Temperaturerhöhung über einen Betrag von wenigen Grad nicht hinausgegangen sein kann.

Der Zuordnung des Neufra-Interglazials zu Holstein entspricht eine Parallelisierung des Hangenden (Riß) mit Saale (Drenthe) und des Liegenden (Mindel) mit Elster. Elster und Saale aber sind genau diejenigen Glaziale des nordischen Vereisungsgebietes, deren Gletscher - wie die von Mindel und Riß im Rheingletschergebiet - die größte Ausdehnung hatten.

Die Liegendschichten des Neufraer Profils, der Auelehm (5, 5a) und die Donauschotter (6) an der Basis des diluvialen Profiles sind in der frühen Mindeleiszeit abgelagert worden. Die grobe Basislage, die an einigen Stellen anzutreffen war, ist der Rest einer Sohlenpflasterung des Flußbettes der Donau aus der Zeit der fluviatilen Erosion zwischen Günz und Mindel. Interessant ist das Vorkommen von Schwemmlöß im Auelehm auf sekundärer Lagerstätte. Dieser Löß könnte günzeiszeitlich, kann aber auch in der frühen Mindeleiszeit abgelagert worden sein. Eine Entscheidung ist schwer zu treffen. Sicher ist aber, daß im Einzugsgebiet der Ertinger Schotterrinne älteres alpines Material (Günz) vorhanden war (Heiligenberger Schotterfeld, SCHÄDEL 1952).

\section{Der Aufschluß von Ertingen \\ Profilbeschreibung}

$6 \mathrm{~km}$ stromaufwärts Neufra in demselben Schotterkörper (Ertinger Schotterfeld) liegt die Gemeindekiesgrube von Ertingen, im Weilertal $2 \mathrm{~km}$ südlich der Ortschaft. Hier ist zwischen 570 und $590 \mathrm{~m}$ Meereshöhe ein weiteres mehrfach gegliedertes Quartärprofil aufgeschlossen (vgl. Abb. 7).

Interessant für die Gliederung sind die obersten 5-6m. Unten lagern etwa $15 \mathrm{~m}$ kristallinreiche Schotter der Ertinger Rinne, die nach oben immer größer werden und schließlich in Schottermoräne oder sehr moränennahe Schotter (5) übergehen. Diese sind zu kompakter Nagelfluh verbacken. Die Nagelfluh ist gekappt und überschliffen von einem Gletscher, der die hangende Grundmoräne (4) abgelagert hat. Aus einzelnen härteren Partien wurden regelrechte Rundhöcker herausgearbeitet. Manche Gerölle sind bis über die Hälfte ihrer ursprünglichen Dicke abgeschliffen worden. Die Schrammen verlaufen $\mathrm{N} 10^{\circ} \mathrm{E}$.

Auf dem hangenden Geschiebemergel liegt verwitterter brauner Lößlehm, darüber Fließerde, ebenfalls verwittert (3, 3a). Geschiebemergel, Lößlehm und Fließerde sind 


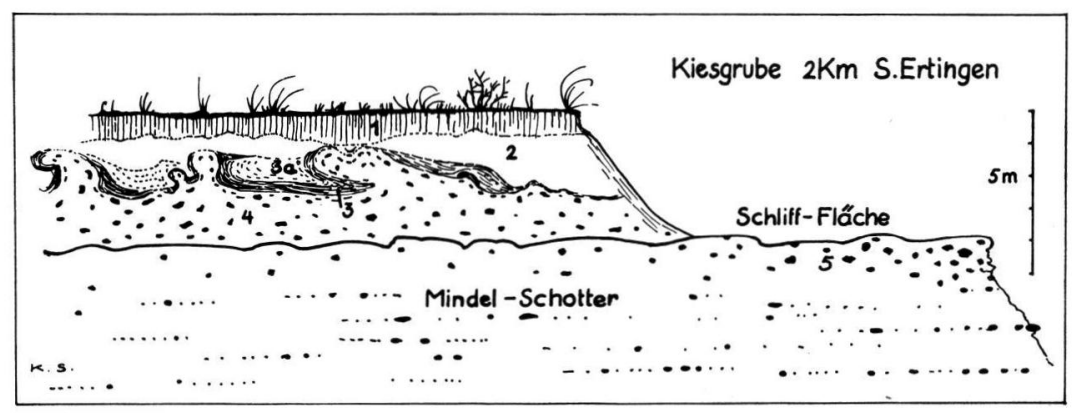

Abb. 7. Kiesgrube S Ertingen, 1 Postwürmzeitliche Bodenbildung auf Moräne und Löß, 2 Löß, 3 Verwitterter Lößlehm und Moräne (alter $\mathrm{B}_{\mathrm{i}}$-Horizont), 3a Verwitterter und frischer Lößlehm, z. T. auch verwitterte Moräne, 4 Frischer Geschiebemergel (Riß), 5 Schottermoräne (Mindel), zu Nagelfluh verbacken.

durch Frostaufbrüche periglazial durchbewegt und verfaltet worden. Diskordant lagert sich darüber ein geringmächtiger frischer Löß (2), der den nacheiszeitlichen Boden trägt. An der linken Grubenwand findet sich im jungen Löß eine begrabene humose Bodenoberfläche, die von Schwemmlöß überdeckt wird und in der Holzkohlereste und urnenfelderzeitliche Scherben gefunden wurden.

Auch hier ergaben Geröllanalysen, die von E. Geiger freundlicherweise durchgeführt wurden, daß zwischen der hangenden Grundmoräne und dem überfahrenen Ertinger Schotter keine petrographischen Unterschiede bestehen.

\section{Deutung des Profiles}

Nach der Ablagerung des Ertinger Schotters und der Schottermoräne in der Mindeleiszeit kam es im Mindel/Riß-Interglazial (Neufra) zur Nagelfluhbildung. Diese Nagelfluh wurde vom Rißgletscher uiberfahren und geschliffen.

Das Vorhandensein der Schottermoräne oder des moränennahen Schotters zeigt, daß der Mindelgletscher bis in die Gegend von Ertingen vorgestoßen war (Abb. 1).

Die periglaziale Durchbewegung der Deckschichten dieses Profils erschwert seine weitere Deutung. Trotzdem ergibt sich recht zwanglos, daß auf den Geschiebemergel der Rißeiszeit (4) eine Lößdecke, die vermutlich lückenhaft war, aufgeblasen wurde. Danach setzte eine Bodenbildung ein (Riß/Würm-Interglazial), die in der Umgebung der Kiesgrube neben dem Löß auch die Moräne erfaßte. Zu Beginn der Würmeiszeit erfolgte die periglaziale Durchbewegung an der damaligen Oberfläche. Später, während des Hochstandes der Würmeiszeit, wurde erneut Löß aufgeweht. Das begrabene Bodenprofil ist nacheiszeitlich, denn die Scherbenreste erweisen sich als der Schussenrieder Kultur zugehörig.

In diesem Profil sind zwei Interglaziale enthalten: Das $M$ indel/Riß-Interglazial, dem die Nagelfluhbildung entspricht, und das Riß/Würm-Interg l a z i a l, dem die Bodenbildung vor der Kryoturbation ihre Entstehung verdankt.

\section{Die Aufschlüsse von Rottum}

Ein drittes Aufschlußprofil bestätigt die Einstufung der Aufschlüsse von Ertingen und Neufra. Es wurde von F. Weidenbach im Anschluß an Neufra und Ertingen auf der Tagung des Oberrheinischen Geologischen Vereins im Frühjahr 1961 vorgeführt.

\section{Der jüngere Rottumer Verwitterungshorizont}

Der Aufschluß befindet sich an der Stelle, wo nach der geologischen Spezialkarte $1: 25000$ Blatt Ochsenhausen (Weidenbach 1937) der äußerste Moränenwall der Rißeiszeit das Rottumtal quert $(500 \mathrm{~m}$ nördlich der Ortschaft Rottum, auf der östlichen Talseite). Vgl. Abb. 8. 


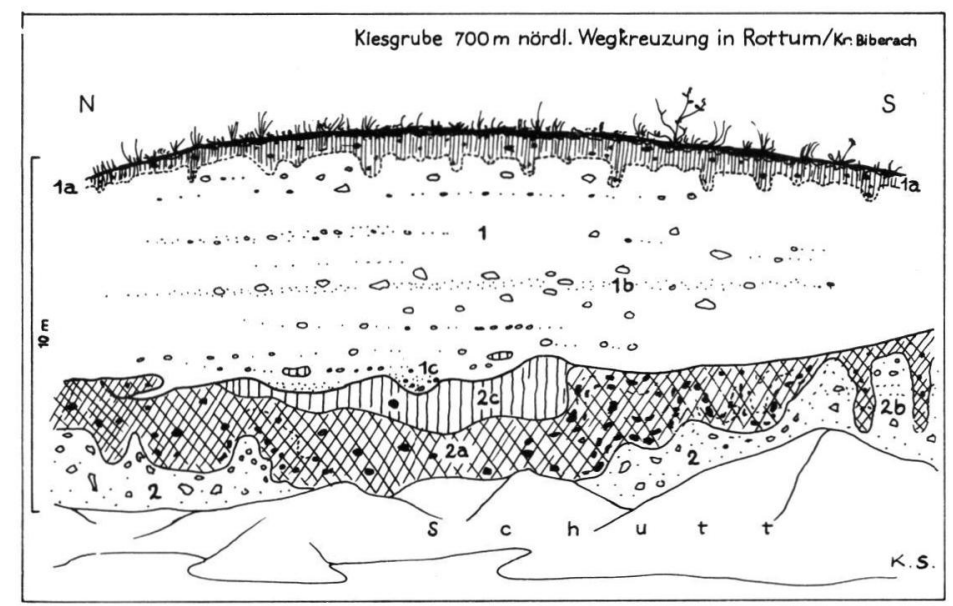

Abb. 8. Kiesgrube N Rottum, Ldkr. Biberach. 1 Schottermoräne der Rißeiszeit, 1a Oberflächenboden, 1b Braune, lehmige Sandiage, 1c Kiesige Rinnenfüllung an der Basis von 1, 2 Stauchmoräne der Mindeleiszeit, 2a Interglaziale Verwitterung zwischen Mindel und Riß, 2b Schlotten, 2c Auelehm.

Unter $6 \mathrm{~m}$ einer teilweise gut geschichteten Schottermoräne der Rißeiszeit (1) liegt eine zweite tief verwitterte Stauchmoräne (2). In beiden Moränen finden sich reichlich kristalline Geschiebe. Auf der verwitterter Stauchmoräne und in dieselbe eingeschnitten, liegt in der Mitte des Aufschlusses ein entkalkter, z. T. gleyfleckiger Auelehm (2c), der offenbar in einer kleinen Mulde abgelagert wurde. Die hangende Schottermoräne hat Fetzen von ihm aufgenommen. Auf beiden Seiten des Aufschlusses taucht unter der verwitterten Moräne frisches Material auf. Die Verwitterungsdecke (2a) ist hier geringer mächtig; dafür erkennt man aber an Verwitterungsschlotten (2b), die tief in das unverwitterte Material eingreifen, daß die Bodenbildung an Ort und Stelle erfolgt ist, bevor der Gletscher, der die hangende Moräne abgelagert hat, heranrückte. Zusammengefaßt ergibt sich für den Rottumer Verwitterungshorizont folgendes Bild: Oben $6 \mathrm{~m}$ Schottermoräne der Rißeiszeit, in der Mitte 0-1,5 m Auelehm, darunter 0,5-2,00 m verwitterte Moräne, an der Basis frische kristallinreiche Moräne des nächstälteren Glazials, also der Mindeleiszeit. Der Verwitterungshorizont ist eine Bildung des $\mathrm{M}$ indel/Riß-Interg lazials.

Der Aufschluß zeigt. daß der Mindelgletscher noch über diesen Punkt hinweggegangen sein muß (vgl. Abb. 1), gibt also einen Anhaltspunkt für die Ausdehnung der Vorlandvereisung.

\section{Der ältere Rottumer Verwitterungshorizont}

Schon seit langem ist in Rottum ein zweiter Verwitterungshorizont bekannt (F. WEIDENBACH 1937). Er ist an mehreren Stellen im Dorf Rottum und etwas südlich davon aufgeschlossen und liegt auf Schottern, die äußerst arm an kristallinen Geröllen und auffallend gut gerundet sind. Dasselbe Aufschlußbild findet sich in der nahegelegenen Kiesgrube bei Hattenburg. Die liegenden Schotter gehören der Zeiler Stufe an. Dies ist der oben angeführte kristallinarme Schotterhorizont, der sich an vielen Stellen des Rheingletschers nachweisen läßt und der häufig eine sehr mächtige rotbraune Verwitterung trägt. Die Überlagerung besteht immer aus kristallinreichen Altmoränen (SCHÄDEL 1950 und A. SCHREINER 1950, 1951). Im mittleren Rheingletscher wird er durch den Heiligenberger Schotter vertreten, der im Gebiet von Heiligenberg. Pfullendorf und Königseggwald neben glazialen Ablagerungen der Ertinger Stufe liegt und sich dort als sicher älter ausweist. Die Zeiler Stufe gehört der Günzeiszeit an. Dieselben Altersverhältnisse ergeben die Rottumer Aufschlüsse, so daß wir in der Nähe dieses Dorfes einmal einen Verwitterungs- 
horizont des G ünz/Mindel-Interglazials haben und zum zweiten einen Ver-

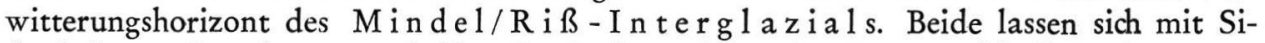
cherheit voneinander unterscheiden durch die andersartige Petrographie ihrer Ausgangsgesteine: Günz ist kristallinarm, Mindel ist kristallinreich, ebenso kristallinreich wie die Moräne der Rißeiszeit, die beide Ablagerungen überdeckt. Außerdem ist die Verwitterungsmächtigkeit, vor allem die Entkalkung, verschieden, die bei den Günzschottern wesentlich mächtiger ist.

\section{Revision der Stratigraphie}

Als Ergebnis der Untersuchungen an den drei Profilen schält sich heraus: In den Altmoränen Oberschwabens sind zwei durch ein Interglazial getrennte Eiszeiten verborgen. Diese schon mehrmals vorher von verschiedenen Autoren geäußerte Vermutung kann bestätigt werden. Darüber hinaus ist es möglich, ein ungefähres Bild von der älteren der beiden großen Eiszeiten zu geben (Abb. 1). Zur Nomenklaturfrage haben wir bereits Stellung genommen. Die von Graul (1952) verfochtene Bezeichnung "Altriß" lehnen wir ab. Entsprechend dem Prioritätsrecht von A. PENCK \& E. BRüCKNER muß man die jüngere Vereisung $\mathrm{Ri} \beta$, die ältere $\mathrm{M}$ indel nennen.

Das hat zur Folge, daß sich im Rheingletschergebiet für alle älteren glazialen Serien eine Altersverschiebung nach rückwärts ergibt: Mindel I (SchäDEL 1950, 1952) wird Günz (was ebenfalls wieder der Ansicht A. PENCK's entspricht). Die mit Sicherheit älteren Schotterriedel von Dorndorf, Eichen-Erlenmoos und Kirchberg (Günz von F. WerdenвACH 1937) müssen Donau II und Donau I genannt werden. Sie entsprechen altersmäßig den Donaueiszeiten von B. EberL (1930), allerdings nur bedingt, da bei EBERL Donau I und Donau II überein ander liegen. Beides ist eine Akkumulation, deren unterer Teil nicht glazial ist. Erst die hangenden Schichten haben echten fluvioglazialen Charakter.

Diese stratigraphische Verschiebung ist notwendig, um Vergleiche mit anderen Vereisungsgebieten, so z. B. mit Norddeutschland, durchführen zu können. Die Korrelation geht überraschend gut, denn in beiden Vereisungsgebieten ist größenordnungsmäßig der gleiche Rhythmus und die gleiche Intensität der Eisvorstöße zu bemerken.

Übersicht über die Abfolge der Glaziale (vgl. Abb. 9):

Wü rm (Weichsel): Die letzte große Kaltzeit ist gekennzeichnet durch eine $\mathrm{m}$ i t t le re Ausdehnung der Vorlandvergletscherung, wobei eine äußere und eine innere Jugendmoräne sich zeitlich nacheinander staffeln (Schaffhausen, Singen). Für ein sogenanntes "Altwürm“ gibt es keinerlei sichere Anzeichen, es sei denn, man verwendet hierfür, wie das R. GERman (1959) irrtümlicher Weise getan hat, spätglaziale Terrassen der Rißeiszeit, die sich nirgends mit Moränen verknüpfen lassen, oder Würmschotter, deren Verwitterungsmächtigkeit durch lokale Faktoren verändert ist.

$\mathrm{R}$ i ß (Saale, Drenthe): Sie umfaßt die vorletzte Kaltzeit, deren Gletscher die g r ö $\beta$ t e A usdehnung hatten. In sich ist sie im Rheingletschergebiet in zwei Endmor ä $\mathrm{n}$ e $\mathrm{nkränze} \mathrm{gegliedert,} \mathrm{die} \mathrm{sich} \mathrm{morphologisch} \mathrm{unterscheiden.} \mathrm{Der} \mathrm{äußere} \mathrm{ist} \mathrm{flach.} \mathrm{Der}$ innere besteht aus einem Doppelwa 11 a us $S$ ta u chmoräne n, die stärker zerlappt sind und zu den größten Moränen im ganzen Gebiet gehören, ähnlich denen des norddeutschen Warthe-Stadiums. Auch bei vorsichtiger Ausdeutung des morphologischen Unterschiedes liegt der Verdacht nahe, daß beide durch einen größeren zeitlichen Zwischenraum mit wärmerem Klima getrennt sind. Der Beweis steht noch aus. - Jüngstes Glied der Rißeiszeit ist eine Terrasse, die in allen Tälern nachzuweisen ist, aber nirgends Verbindung mit Moränen hat, die sogenannte "Jungrißterrasse" von GRAUL. Da in ihr verschiedentlich schon das Äquivalent des "Altwürm“ vermutet wurde, sei hier angeführt, daß sie sich nirgends mit Jungmoränen verzahnt. 


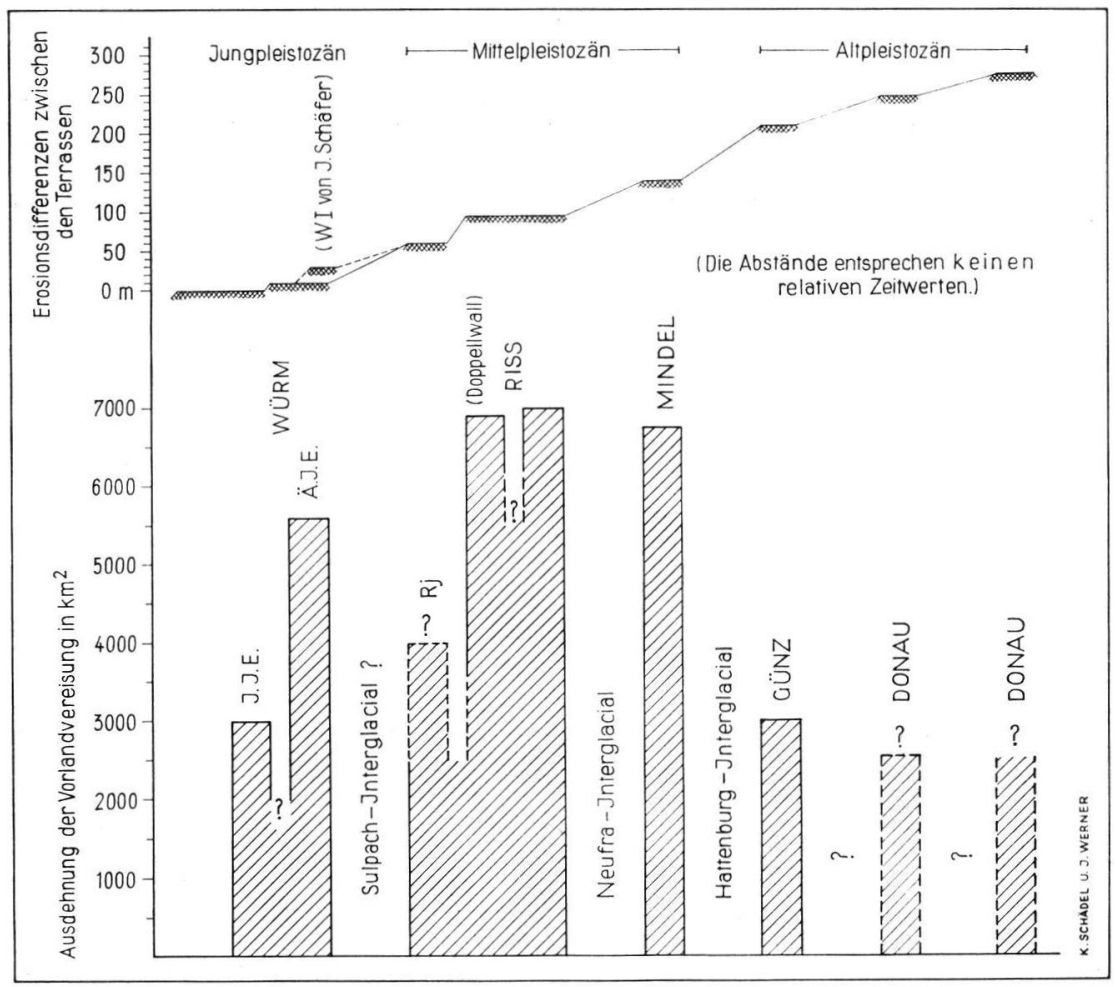

Abb. 9. Schematische Ubersicht über die Folge der Glaziale und Interglaziale im Rheingletschergebiet. Die Erosionsdifferenzen verstehen sich von der Basis einer Aufschüttung bis zum Terrassenniveau der nächst älteren Aufschüttung.

M in d el (Elster): Hierbei handelt es sich um eine Kaltzeit, deren Vorlandvereisung im Rheingletschergebiet von der Größenordnung der Rißvereisung (Abb. 1) war. Die Form des Mindelgletschers ist anscheinend weniger ausgeprägt gewesen als die des Rißgletschers; seine Beckenbildung geringer.

Günz: Dies ist die älteste sichere Vereisung im Rheingletschergebiet mit einer geschlossenen glazialen Serie. Die Ausdehnung des Vorlandeises war klein, kle in e r a ls i $m$ W ü r m. Die Größe entsprach etwa dem Singener Stand der Würmvereisung. Völlig andersartig ist die petrographische Ausbildung der Moränen und Kiese. Im ganzen Rheingletscher, von lokalen Ausnahmen abgesehen, ist der Anteil an kristallinen Geschieben bedeutend geringer, aber auch andere Merkmale lassen erkennen, daß es sich bei einem hohen Prozentsatz von Geröllen um umgelagerte tertiäre Nagelfluh handelt. Die Meinung, die $H$. Graul 1953 vertreten hat, es handele sich um eine "Argenvergletscherung “, fußt gleichfalls auf dieser Erscheiung, ist aber nicht zutreffend, da einzelne Moränenschmitzen Bündner Material enthalten.

Don a : Außerhalb der Altmoränen liegen hochgelegene Schotterterrassen, deren Riedel im Kartenbild auf beiden Seiten sägezahnartig zerschnitten sind. Mit der Günzeiszeit lassen sie sich wegen ihrer großen Höhenlage nicht verbinden. Ihre Verwitterung ist außerordentlich tief, meist sind keine frischen Schotter mehr vorhanden. Aus dem Verhalten ihrer Gefällsprofile im Vergleich zu anderen pleistozänen Profilen und aus wenigen Schotteranalysen hat SCHÄDEL (1950) geschlossen, daß ihr Eisrand weiter alpenwärts gelegen haben muß, also der dazugehörige Vorlandgletscher verhältnismäßig klein gewesen ist. 


\section{In terglaziale}

Für die Verwitterungshorizonte, die im Rheingletschergebiet Interglaziale repräsentieren, schlagen wir Lokalnamen vor: für die Zeit zwischen Günz- und Mindeleiszeit $\mathrm{H}$ a t te n burg, nach dem Verwitterungshorizont in der Gemeindekiesgrube Hattenburg, südlich Ochsenhausen, für das Interglazial zwischen Mindel- und Rißeiszeit $\mathrm{Ne}$ u $\mathrm{r}$ a, nach dem oben beschriebenen Aufschluß.

Jüngere, ohne $Z_{w}$ eifel interglaziale Bildungen sind zwar vorhanden, z. B. nordöstlich Sulpach (Karrestobel, zuerst beschrieben von A. PENCK \& E. BRÜCKNER 1909), lassen sich aber nur bedingt stratigraphisch verwerten, weil über Liegendes und Hangendes keine eindeutigen stratigraphischen Aussagen möglich sind. Die Grenze zwischen Würm und Riß muß noch gezogen werden. Die Ergebnisse von R. German (1959) sind durch seine eigene Revokation (Vorträge, gehalten $1961 / 2$ in Stuttgart und Tübingen) hinfällig geworden.

\section{Lit e r a tur}

AltemüllLer, H.-J.: Mikroskopische Untersuchungen einiger Löß-Bodentypen mit Hilfe von Dünnschliffen. - Z. Pflanzenern. Düng. Bodenk. 72, 152-167, 1956.

voN Der Brelie, G.: Die pollenstratigraphische Gliederung des Pleistozäns in Nordwestdeutschland. - Eiszeitalter und Gegenwart 6, 25-40, 1955.

EberL, B.: Die Eiszeitenfolge im nördlichen Alpenvorlande. Ihr Ablauf, ihre Chronologie auf Grund der Aufnahmen im Bereich des Lech- und Illergletschers. - Augsburg 1930.

Florschürz, F.: The Subdivisions of the Middle and Young Pleistocene up to the Late-Glacial in the Netherlands, England and Germany, mainly based on the Results of Paleobotanical Investigations. - Geologie en Mijnbouw (N. S.) 19, 245-249, 1957.

Geiger, E.: Untersuchungen über den Geröllbestand im Rheingletschergebiet. - Schweiz. Min. u. Petr. Mitt. 28, 274-287, 1948.

German, R.: Die Würmvereisung an Rhein- und Illergletscher zwischen Federseebecken und Günztal. - Geologica Bavarica 43, 3-73, München 1959.

Graul, H.: Zur Gliederung der mittelpleistozänen Ablagerungen in Oberschwaben. - Eiszeitalter u. Gegenwart 2, 133-146, 1952. - - Bemerkungen zu einer geologischen Übersichtskarte des Iller-Riß-Gebietes. - Z. deutsch. geol. Ges. 105, 517-524, 1953.

Hallik, R.: Die Vegetationsentwicklung der Holstein-Warmzeit in Nordwestdeutschland und die Altersstellung der Kieselgurlager in der südl. Lüneburger Heide. - Z. deutsch. geol. Ges. 112, 326-333, 1960.

Käsz, W. u. Werner, J.: Farbmessungen an oberschwäbischen Böden. - Geol. Jb. 79, 845-862, 1962.

Kolumbe, E.: Nachweis einer Wärmezeit zwischen Alt- und Mittel-Riß in Niedersachsen. - Mitt. geol. Staatsinst. Hamburg 22, 22-27, 1953.

Kubiena, W. L.: Entwicklungslehre des Bodens. - Wien 1948.

Kundler, P.: Zur Charakterisierung und Systematik der Braunen Waldböden. - Z. Pflanzenern. Düng. Bodenk. 78, 209-232, 1957.

Penck, A. u. Brǘckner, E.: Die Alpen im Eiszeitalter, 3 Bde., Leipzig 1902-1909.

PICARD, K.: Zur Untergliederung der Saalevereisung im W Schleswig-Holsteins. - Z. deutsch. geol. Ges. 112, 316-325, 1960.

Schädel, K.: Die Deckenschotter des Rheingletschers. - Diss. Tübingen (Mskr.) 1950. - - Die Stratigraphie des Altdiluviums im Rheingletschergebiet. - Jber. Mitt. oberrh. geol. Ver., N. F. 34, 1-20, 1952.

Schreiner, A.: Die Entstehung des Wurzacher Beckens. - Diss. Tübingen (Mskr.) 1950. - - Diluvialgeologische Untersuchungen im Wurzacher Becken (Oberschwaben). - Jber. u. Mitt. oberrhein. geol. Ver., N. F. 33, 78-88, 1951.

Walter, H.: Arealkunde = Einführung in die Phytologie, III: Grundlagen der Pflanzenverbreitung, II. Teil. - Stuttgart 1954.

WeIdENBACH, F.: Erläuterungen zur geologischen Spezialkarte von Württemberg $1: 25000$, Blatt Waldsee. - Stuttgart 1936. - - Erläuterungen zur geologischen Spezialkarte von Württemberg 1:25000, Blatt Biberach. - Stuttgart 1937. - Bildungsweise und Stratigraphie der diluvialen Ablagerungen Oberschwabens. - N. Jb. Mineral usw. Beil.-Bd. 78 B, 66-108, 1937. - - in: Graul, H., Schaefer, I. und Weidenbach, F.: Quartärgeologische Exkursion durch die Riß-Lechplatte. - Geologica Bavarica 6, 91-117, 1951. - - Zur Entstehung und Lagerung der diluvialen Schichten im Donaumoos unterhalb Ulm. - Jh. Geol. Abt. Württ. Statist. Landesamt 1, 120-127, 1961. 
WEYL, R.: Schwermineraluntersuchungen an Bodenprofilen. - Z. Pflanzenern. Düng. Bodenk. 57, 135-141, 1952. - - Schwermineraluntersuchungen an eiszeitlichen Ablagerungen der RißLech-Platte. - Geologica Bavarica 14, 107-123, 1952.

Woldstedt, P.: Das Eiszeitalter. 2. Bd.: Europa, Vorderasien und Nordamerika im Eiszeitalter. 2. Aufl. Stuttgart 1958.

Manuskr. eingeg. 1. 6. 1962.

Anschrift der Verf.: Dr. Karl Schädel und Dr. Jörg Werner, Geol. Landesamt Baden-Württemberg, Freiburg i. Br., Albertstraße 5.

\section{Nachtrag während der Drucklegung}

Während der Drucklegung erschien im vierten Quartalsheft von Petermanns Geograph. Mitt. 1962 eine Arbeit von H. Graul mit einem bodenkundlichen Beitrag von K. Brunnacker mit dem Titel: „Eine Revision der pleistozänen Stratigraphie des schwäbischen Alpenvorlandes“. Es handelt sich dabei um eine Parallelarbeit mit der unsrigen. Unter anderem werden dieselben Aufschlüsse beschrieben und ähnliche, wenn auch im einzelnen abweichende Folgerungen für die Stratigraphie gezogen. Wir haben unsere Auffassung bereits auf der Tagung des Oberrheinischen Geologischen Vereins in Ulm 1961 (Exkursion am 8. 4. 1961) vertreten (Führer zu den Exkursionen d. 82. Tagung des Oberrh. Geol. Ver., Arbeiten aus dem Geol. Paläont. Inst. T. H. Stuttgart, Stuttgart 1961; Jher. u. Mitt. oberrh. geol. Ver. N.F. 43. 1961, Seite XII-XIV). Zum Vergleich und Verständnis beider Arbeiten die Gegenüberstellung verschiedener Namen einiger identischer Lokalitäten, die für die stratigraphischen Fo!gerungen beider Arbeiten grundlegend sind:

H. Graul 1962

Kgr. Greut-Schlatt, SE von Riedlingen

Kgr. Binsenstock, SE Ertingen

Kgr. bei Rottum, Hof Riedwanger
SCHÄDEL - WERNER

Kgr. Neufra, beim Vogelwäldle

Gmde.-Kgr. von Ertingen im Weilertal

Kgr. 700 m nördlich Wegkreuzung Rottum 